\title{
Model selection for continuous commissioning of HVAC-systems in office buildings: a review
}

\author{
Verhelst J. ${ }^{1,2, *}$, Van Ham G. ${ }^{1}$, Saelens D. ${ }^{1,2}$, Helsen L. ${ }^{1,2}$ \\ Celestijnenlaan 300C, 3000 Leuven, Belgium
}

\begin{abstract}
This paper presents an overview of literature and procedures about real-life, state-of-the-art implementations of model-based (MB) Continuous Commissioning $(\mathrm{CCx})$ in office buildings. The focus is on the building- and HVAC-models used for each of three distinct CCx-domains: The identification of energy conserving opportunities (ECOs), fault detection, diagnosis, evaluation and overhaul (FDDe) and model-based control (MBC). For each domain, the relations between chosen model structure, model order, parameter estimation procedure, available sensor data quality and calculation power are highlighted. These insights are critical for office building managers, BEMS manufacturers and researchers involved or interested in the selection and implementation of MBCC strategies.

The analyses indicate that the chosen model order and parameter estimation technique depend highly on available calculation power and data availability. Full model-sharing between different subtopics is rarely performed, presumably due to the diversity of model requirements for each CCx-domain. Several model structures and parameter estimation procedures -e.g. multi-step-ahead and subspace identification- are recurring frequently within one domain -e.g. MBC-. Also, both within and between $\mathrm{CCx}$-domains, the exchange of available expert knowledge and measurements for parameter estimation improves the accuracy of the resulting models.
\end{abstract}

Keywords: HVAC, control, office building, review, model, FDDe, Continuous Commissioning

\footnotetext{
*Corresponding author

${ }^{1}$ KULeuven

${ }^{2}$ Energyville

Preprint submitted to Elsevier
}

February 1, 2017 


\section{Contents}

\begin{tabular}{lll}
\hline 1 & Introduction & 2
\end{tabular}

\begin{tabular}{|lll}
2 & Modelling practices to represent Buildings and HVAC & 10
\end{tabular}

2.1 Model quality indicators . . . . . . . . . . . . . 13

2.2 Model Identification . . . . . . . . . . . . . . . . . . 14

2.3 Data sources for parameter estimation $\ldots \ldots \ldots . . \ldots 15$

3 Models for Benchmarking (BM), Performance Estimation (PE) and Energy conserving opportunities identification (ECOI) 16

3.1 Requirements of BM,PE,ECO-ident models . . . . . . . . . 16

3.2 Implementations of BM, PE and ECOI models . . . . . . . . 17

4 Models for Fault detection, diagnosis and evaluation (FDDe) 19

4.1 Requirements for FDDe models . . . . . . . . . 20

4.2 Implementation examples of FDDe models . . . . . . . . . 21

5 Models for Model based control (MBC) 21

5.1 Requirements of MBC-models . . . . . . . . . . . . 21

5.2 Implementation examples of MBC-models $\ldots \ldots . . . . .23$

$\begin{array}{lll}6 & \text { Discussion } & 24\end{array}$

\begin{tabular}{lll}
\hline 7 & Conclusion & 32
\end{tabular}

8 Nomenclature 34

\section{1. Introduction}

Heating, ventilation and air conditioning (HVAC), used to reach and maintain indoor comfort during occupied periods, is responsible for around $40 \%$ of the energy use in office buildings [1]. The annual primary energy use in office buildings in Europe varies from 100 to $1000 \mathrm{kWh} / \mathrm{m}^{2} / y$ of conditioned floor space $[2]$. This large spread can be explained by variations in building usage, location, orientation, status and control of HVAC and lighting installations, use and type of office equipment and operating schedules [3].

Many buildings and HVAC are operated today in a suboptimal manner. ${ }_{11}$ Several studies (e.g. [4, 5]) mention average energy conserving opportunities 
(ECOs) between 15 to $30 \%$ of building energy use, through improvements of operational strategies, on top of savings associated with major retrofits in the same buildings. Roth et al. (2005) 6 estimated potential savings of 3 to 17 billion $\$$ per year for the top 13 ECO implementations (ECOI) in the USA alone 7 . In Europe, potential electrical savings alone are estimated between 61 to $100 \mathrm{kWh} / \mathrm{m}^{2} / \mathrm{y}$ for office buildings, resulting in potential cost savings above 6 billion $€$ per year when extrapolated to all office buildings in Europe [1.

The process of following up and improving building and HVAC performance during their lifetime is grouped under the label "Commissioning" (Cx). A US industry survey (in 2000) in California estimated that only $0.03 \%$ of existing buildings and $5 \%$ of new construction had been commissioned (PECI 2000). A follow-up survey in 2005 estimated that well below $5 \%$ of existing buildings and as much as $38 \%$ of new constructions had been commissioned [8]. These figures indicate that there is a rising awareness of the importance of $\mathrm{CCx}$, at least for new buildings. But also for existing installations, there is a daunting potential for improvement. In a small study (20 chillers) in California [9],70\% of the investigated systems were impacted by faults and about $40 \%$ had more than one fault. Servicing was economically justified for about $40 \%$ of the units.

The CCx process is a long, continuous, active monitoring and correction process, comparable to the PDCA circle often found in industrial evaluation cycles (see figure 1). Note that $\mathrm{Cx}$ of buildings always involves people, and not just technology $[10$. Model based continuous commissioning (MBCC) can assist, enhance and support the decision quality and ease of implementation of most of these phases, as will be shown in implementation examples in this paper, but will not -yet?- replace the requirement for human involvement [11. Each of these evaluation cycles can drive the implementation of ECOs or other energy saving strategies.

\section{Objectives of this review}

This paper aims to present an overview of literature and procedures about state-of-the-art implementations of model-based (MB) Continuous Commissioning $(\mathrm{CCx})$ in office buildings. The focus is on the building- and HVAC-models used for each of three distinct CCX-domains: The identification of energy conserving opportunities (ECOs), fault detection, diagnosis, evaluation and overhaul (FDDe) and model-based control (MBC). For each domain, the relations between chosen model structure, model order, parameter estimation procedure, available sensor data quality and calculation 


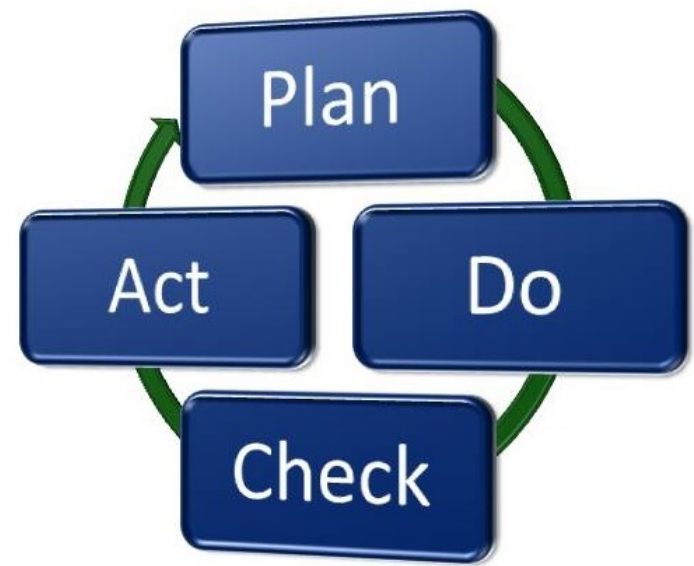

Figure 1: $\mathrm{CCx}$ is a cyclical process of Planning, Doing, Checking and Acting (or adjusting) that can be represented schematically by the PDCA-circle.

power are highlighted.

Drivers for Commissioning (Cx)

There are multiple drivers that explain the increasing implementation of Cx for HVAC systems in buildings, especially in the last decade. Compared to older office buildings, most modern buildings have more stringent comfort 55 demands, increased complexity of HVAC systems, increased electrification and automation of building and HVAC processes. This results in a growing number of interactions between HVAC-components. Simultaneously, typically reduced over-sizing safety factors are applied to the installed HVAC production capacity, due to improved insulation, improved HVAC controllability and improved awareness of effects on building energy performance. These changes go hand in hand with an explosion of control and analysis possibilities. The internet of things (IoT) and big data (BD) paradigms lead to more affordable and powerful BEMS, able to gather, process and respond to a broad range of information resources.

Several market-related drivers also act as a catalyst towards increased interest in CCx, such as increasing energy costs, the steady decline of fossil fuel reserves and enforcement by legislation. The direct economic impact of $\mathrm{CCx}$ through lowering the yearly energy related expenditures, in combination with relatively low investment costs of most $\mathrm{CCx}$ measures, makes that the internal rate of return (IRR) and return on CCx-investments (ROI) often are favourable, resulting in a short pay-back period. For most cases, this 
(simple) payback-period lies between 1 and 5 years 12,13 . A few countries throughout the world have obliged their members or member states over the last few years to measure, verify (and share) energy performance of existing (public) buildings. Examples are the Energy-star (USA) and Energy Efficiency Services (Europe) programs. These drivers explain why $\mathrm{CCx}$ has received wide attention recently, especially in the USA and in the UK [14, 15].

\section{Definitions}

Before diving into the steps and sub-domains of a typical $\mathrm{Cx}$ process, the terminology used in this paper is clarified. Definitions of key concepts are given in footnotes of this section.

Commissioning $(\mathrm{Cx})^{3}$ is a process that aims at increasing understanding, disaggregation of utility consumption and identification, selection and evaluation of ECO and potential savings. $\mathrm{Cx}$ can be applied to detect HVAC deficiencies in components or distribution systems, but can also detect and identify calibration, maintenance, scheduling, start stop or other control deficiencies (any fault with high occurrence and large impact). Variants of Cx are re-commissioning, which stresses the repeating nature of the process, and retro-commissioning, stressing a one-shot tune-up after a long commissioning-free period.

Continuous commissioning $(\mathrm{CCx} \text { or } \mathrm{CC})^{4}$ consists of a continuous performance evaluation in order to maintain, improve and optimise the performance of building systems during building operation and occupancy [19, 20]. It also encompasses the process of identifying substandard (faulty) domaining of any equipment, sensors and systems (including control systems).

Model based Commissioning (MBCx) ${ }^{5}$ aims at bringing and maintaining

\footnotetext{
${ }^{3} \mathrm{Cx}$ is defined $[16$ as "the process of ensuring that systems are designed, installed, nominally tested and capable of being operated and maintained to perform in conformity with the design intent". Later, 17 this was rephrased as: "a quality-oriented process for achieving, verifying, and documenting that the performance of facilities, systems, and assemblies meets defined objectives and criteria".

${ }^{4} \mathrm{CCx}$ or ongoing commissioning $[18$ is a systematic process of observing, measuring and evaluating the performance of building systems to identify and implement operational and maintenance improvements and to ensure their continued performance over time in existing buildings (PECI 2003), in contrast to a one-time commissioning during the first years of building occupancy only.

${ }^{5} \mathrm{MBCx}$ is a systematic process by which proper installation and operation of building
} 


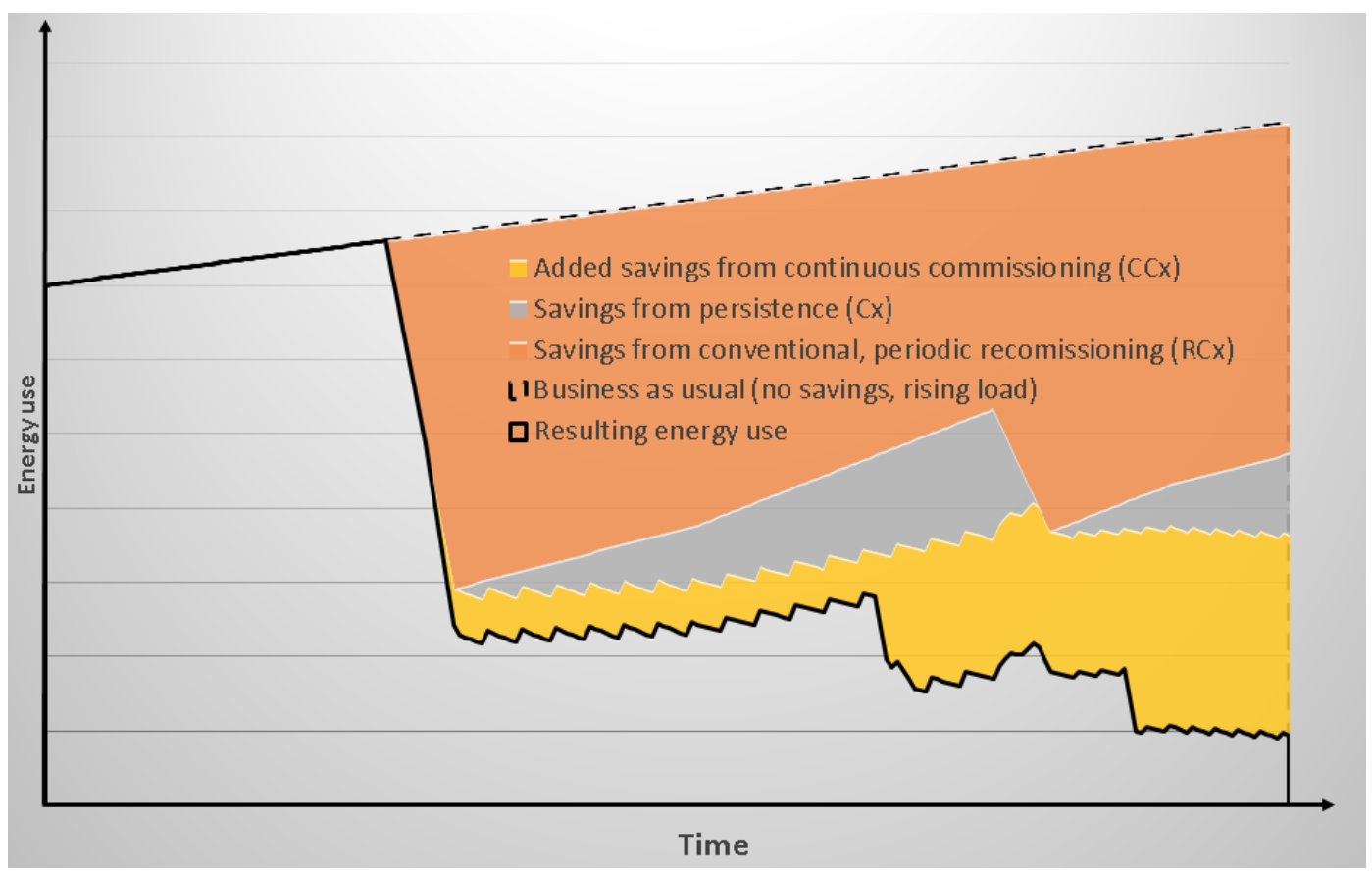

Figure 2: Monitored KPI of building performance (e.g. energy use) as a function of time, with highlighted savings related to $\mathrm{MBCx}$ application, due to improved operational HVAC-performance, overhaul of identified HVAC-faults and reduced repair and maintenance costs. Recreated based on: [7]

system efficiencies (low energy use, high comfort levels) near the levels stated in the building design phase (as-built performance), as shown in figure ??. In this process, HVAC-systems are often a primary target, due to their high energy use in buildings and the often non-trivial effects of occurring faults, but it can also be applied to other building technologies, e.g. lighting equipment, sanitary installations, etc. Applications such as lighting controls and domestic hot water use are excluded in this study, since the focus is placed on CCx of HVAC-systems and building envelope.

Model-based Continuous Commissioning (MBCC) $]^{6}$ encompasses both MBCx and CCx. Note that the same abbreviation (MBCC) is also used in a similar context, as an acronym for "Monitoring-based continuous commission-

systems and equipment are compared with a reference model of expected performance, adjusted when necessary to keep and improve equipment performance.

${ }^{6} \mathrm{MBCC}$ is defined as: the process of using (reduced order) models of the building, HVAC-system and user behaviour to support CCx subdomains 
ing". The difference with model-based $\mathrm{CCx}$ (MBCC) as defined here, is that monitoring-based CCx always uses sensory feedback (measurements) to compare and evaluate current and historic building performance. In contrast, model-based CCx highlights the use of a reference model, which can be constructed either based on building measurements (as in monitoring based $\mathrm{CCx}$ ), or based on other information sources, e.g. expert knowledge or design data. In this sense, the definition of model-based CCx is slightly broader than monitoring-based CCx. On the flip-side, monitoring based CCx could also include domains using model-free algorithms, such as Artificial Neural Networks (ANN), which are excluded from MBCC as defined here. Apart from model free applications -not covered in this paper-, monitoring based CCx can therefore be seen as a subset of data-driven black-box (BB) MBCC.

\section{Three sub-domains of $M B C C$}

The HVAC system in a building uses energy to maintain a set of (thermal) comfort constraints within the building. Both comfort generation and energy use can be kept under check using MBCC, through the implementation, follow-up and execution of corrective actions in one or more of these 3 subtopics:

(A) ECOI: Identification of economically attractive energy conserving opportunities (ECOs). This sub-domain includes benchmarking (BM) against other references, performance evaluation (PE) of current performance against historic performance and impact estimation of future ECO Implementation: ${ }^{7}$ (ECOI).

(B) FDDe: Fault detection, diagnosis, evaluation and overhaul. This subdomain uses data to detect potential faults in HVAC sensing or operation, diagnosing fault location, severity and its impact. It often provides advice for (automatic or manual) corrective overhaul actions.

\footnotetext{
${ }^{7}$ These three sub-domains of CCx (BM, PE and ECOI) are discussed simultaneously, since they share a common goal and evaluation criterion: evaluating the current building performance, compared to a reference. Only the reference varies between the three subdomains: for BM, the reference is an exemplar building with similar layout or domain, for $\mathrm{PE}$, the reference is historic performance of the building under investigation, while for ECOI, the reference is the building under investigation, with an alternative building configuration or adapted HVAC installation.
} 
(C) MBC: Model based control. This sub-domain consist of all model based HVAC controllers, used to obtain a weighted trade-off between (minimal) energy use and (maximal) thermal comfort (reaching target setpoints or thermal comfort bands) during actual or scheduled occupancy. This category ranges from a simple outdoor air temperature reset (OATR) open loop controller, which resets the supply water temperature based on measured averaged ambient temperature using a steady-state building model, up to a (robust) model predictive control(ler) (MPC), that uses a stochastic or deterministic dynamic model to estimate the building response to weather and occupancy disturbances in order to calculate the most optimal HVAC control settings.

\section{Knowledge gap identification, goal and contribution of this paper}

Although advanced BEMS, energy control management systems (ECMS) and faults in HVAC are abundant in existing office buildings, it is difficult to set up unified rules or recommendations for BM, FDDe and MBC, since the office building stock and usage is very heterogeneous. The CCx process -and also the model based subset of $\mathrm{CCx}$ - aims to streamline, standardise and partially automate this process.

Multiple authors have published Cx procedures, either for the whole Cx-domain or for specific sub-domains. Among others, Cx guidelines are available from PG\&E, PECI (2003), BNL (2005), TA\&M (2002), Haves (2008), Roth (2008) and Redmann (2003) [21, 22, 23. Unfortunately the used nomenclature is neither rigorously nor uniformly defined. Also, not all sections or procedures are applicable to MBCC.

Three major guidelines (a more extensive list is given in [24|) provide guidance for energy performance measurement and verification (M\&V) of existing building energy use:

- The International Performance Measurement and Verification Protocol (IPM\&VP) 25

- The ASHRAE Guideline on Measurement of Energy and Demand Savings 26

- The M\&V Guidelines for Measurement and Verification for Federal Energy Projects 27

All of these protocols and guidelines include the development of a model calibrated against measurement data in some variants of the analysis (e.g. 
IPM\&VP, option D). The required model structure, model order and parameter estimation method are often left unspecified in these guidelines. Instead, they have to be determined by the modeller based on his knowledge, available time, goals and budget [28].

In this paper, a review of related literature and procedures applied to implemented MBCC cases in office buildings is presented per sub-domain. Specifically, following research questions are investigated:

1. Which models and parameter estimation procedures are typically used in real-building MBCC-implementations for each CCx sub-domain?

2. Are there models, model selection techniques, parameter estimation methods or training datasets which are recurring (and possibly reusable) for multiple CCx sub-domains?

3. What are the minimal data and calculation power requirements for each CCx domain?

The focus of this paper lies thus on the model requirements and parameter estimation procedure used for implementation of $\mathrm{MBCC}$ in new and existing office buildings. To our knowledge, (most of) existing research publications on implementation of $\mathrm{CCx}$-including some very thorough reviewsmainly focus on the potential and realised energy savings of a specific model application in a case study implementation, not on the method and models used during the implementation.

Another contribution of this paper is the investigation of the re-use potential of the model structures and parameter estimation procedure over the different sub-domains of MBCC. If re-usability is feasible, it allows cost sharing of experimental data collection and model generation over multiple CCx sub-domains. Thereby, two major problems in CCx market penetration [6] may be alleviated: the economical investment barrier and the economical uncertainties of CCx savings.

Finally, parameter estimation procedures and model structures are compared, based on their input data and calculation power requirements. The hypothesis is made that (part of this) additional variability can be explained by on-site sensor data availability (number and accuracy of sensor inputs) and on-site calculation power availability, leading to a different choice in complexity of parameter estimation and implemented MBCC algorithms. These two aspects are combined in qualitative tree-charts, which present 
the selected model structure and parameter estimation method used in reported implementations in relation to the availability of calculation power and sensor data. This representation can assist in selecting an appropriate model structure for applications, based on available hardware or budget. These three unique and novel approaches are, to the knowledge of the authors, not yet performed by other researchers in any of the investigated literature on MBCC of HVAC systems in offices, at (supervisory) building level.

The following three sections contain a historic overview of model types, structures and model orders, which were used in CCx-implementations in each sub-domain. Each of these sections is structured as follows: first, the typical sub-domain requirements and corresponding model quality requirements are given, based on experience from experts in these fields. Subsequently, a summary of well-documented, implemented cases is presented in tabular form. These tables are analysed and compared in the penultimate section of this paper. The last section contains conclusions drawn based on the insights springing from these analyses.

\section{Modelling practices to represent Buildings and HVAC}

In order to apply MBCC, it is crucial to start from a suitable model. Building and HVAC models are merely an approximation of reality and therefore invariably contain uncertainty (inaccuracies), including a-priori and a-posteriori epistemic (reducible in theory) and aleatory (irreducible) sources of uncertainty $[29 \mid$. The irreducible sources of uncertainties cannot be identified uniquely, even by high-order, non-linear models. However, to be functional for MBCC, a lower-order model with a bounded inaccuracy in response to relevant excitations often suffices, and is even preferred for implementation over a higher order alternative, since parameter estimation and implementation are simplified |30|.

There are innumerable types and subtypes of models. To obtain a representative model of reality, useful for MBCCx, four main choices have to be made:

a: The system boundary under consideration

b: The model structure,

c: The model order 
d: (A reasonable estimate of) model parameter values.

The resulting model approximates the relevant dynamics of the system under investigation, and can therefore be used for $\mathrm{MBCCx}$ implementations. These four model aspects are discussed in the next paragraphs and also re-appear in the summarising tables in later sections specifically for each sub-domain.

The system boundary of an MBCCx model is ideally confined to the specific system under investigation, as long as external interactions can be neglected or defined as inputs. For example, in most scenarios for an HVACplant ECOI analysis, it is reasonable to model only the plant equipment response to a fixed building HVAC demand profile while excluding other building disturbances. On the other hand, to identify for example an MPC controller model of the heating plant in a concrete core activated (CCA)building, this will not suffice, since dynamic interactions between HVAC and building are substantial. Here, both the HVAC-system and building have to be simulated in the control model.

As model structure for $\mathrm{CCx}$, often a resistance- $(\mathrm{R})$ or resistance-capacitance (RC) analogy-based state-space (SS) or transfer function (TF) model is used. For building models, the real architecture is frequently lumped to a low number (1 to 5 ) of rectangular uniform zones per building (shell), resulting in only minor errors for most building and HVAC architectures [31]. These lumped zones, consisting of areas with similar temperature profiles, building function, HVAC system and comparable disturbances are often assumed to have uniform temperature (well mixed zone). These simplifications lead to a more limited set of parameters (compared to a detailed, high-order model), which results in a lower uncertainty on the parameters, and faster emulations.

The chosen model structure (e.g. number of $\mathrm{R}$ and $\mathrm{C}$ parameters) per type of building component and assumed disturbances mainly depend on the type and size of the building, its application and location (climate) [14]. For ECO analysis of HVAC plants, the useful model order can vary widely. If the goal is a gross comparison of HVAC technologies over a wide range, very low order models can be suitable (e.g. 1-2 parameter models are sufficient to accurately compare average seasonal performance of HVACcomponents). On the other hand, if the performance of two near-identical subsystems is evaluated, the selected models will be of higher order.

The model order relates to the number of states $(\# s)$ used to approximate the building and HVAC system under investigation. Closely linked to 
this metric, are the number of controllable inputs $(\# u)$ and number of disturbances $(\# d)$. In many cases a modelled state can be measured physically, but sometimes this is not economically feasible. In that case, a measurable output $(\# y)$ can be included in the model, that can be used for parameter estimation, reference tracking or emulation. The assumed relation between inputs, outputs, states and disturbances is given by the model structure and chosen parameter values.

To obtain model parameter values for existing buildings and HVAC systems, estimation of grey box (GB) or black box (BB)-parameters are mostly performed based on available measurement data, using autoregressive moving average (ARMA), Autoregressive moving average model with exogenous inputs (ARMAX) or Genetic algorithm (GA) parameter estimation frameworks. For new buildings, measurement data is by definition unavailable. There, a WB-approach is mostly applied, resulting directly in a model structure, including estimates of parameter values, based on building and equipment properties. A hybrid approach is also possible, where a detailed WB-model is used to generate emulation data, that is subsequently used to identify parameters for a lower order model.

For energy use estimation (PE) of a specific building, 2-parameter, 1state (linear) and 4-parameter, 1-state (bi-linear) energy signature models (energy use vs average ambient temperature) are often used, calibrated using hourly or daily historic data. These low order models are able to quantify around $60 \%$ of available variance in building-wide heat and electricity use in offices in cold climates [32. On the other side of the spectrum, for detailed zonal building-shell response models, heavy walls are often approximated using the RC-analogy, with a 2R1C up to 5R3C-approximation for the walls, and $1 \mathrm{C}$ for the air and furniture heat capacity [33], increasing the model order by one capacity per heavy building component.

For FDDE, two disjunct approaches are feasible: an installation-focussed high-order WB or expert model can be tuned to a real (assumed fault-free) implementation situation. During subsequent monitoring, a large deviation from this baseline indicates a fault. A competing approach is to train several component-specific models in supervised manner, both in fault-free and fault-present situations, and classify the behaviour to either of the groups during subsequent monitoring. Typically, for FDDE, high order models with multiple inputs and states are used, to increase fault sensitivity, robustness and to allow detailed classification of faults.

In most supervisory level MBC applications, HVAC installations are rep- 
resented by reduced order, static models. This is justified since the control dynamics, switching frequency, lag times and time steps in HVAC control of offices are often much smaller (range of seconds to minutes) than the time constant associated to the building response and KPI-variations (tens of minutes to hours). Therefore, when modelling for supervisory level MBC or PE, only the (tens of minutes to hours) dynamics associated with the building envelope structure and occupants should be identified and modelled accurately, while the HVAC installation model can be static [34]. On the other hand, when implementing low level MBC (e.g. distributed model based control, D-MBC) or ECOI of a specific HVAC-controller or combination of installations, dynamic models of the HVAC-installation (with their associated parameter estimation difficulties) are more effective, since lowlevel control typically operates in the range of the dominant frequencies of the building response and disturbances.

\subsection{Model quality indicators}

The quality of model fit is typically evaluated based on the proportion of explained variance $\left(\mathrm{R}^{2}\right)$ between prediction and cross-validation data, or by comparing the mean square error (MSE), normalised root mean square error (N-RMSE) and the covariance of the root mean square error (cv(RMSE)) values between candidate models [16]. An alternative evaluation method for the goodness of fit and model applicability, is the likelihood ratio test (LRT) 35.

If in-operation (emulated or measured) data is available, the in-operation (multi-step ahead prediction) performance can be compared to theoretical or expected performance for an indication of model fitness. To assess the portion of un-modelled dynamics of the system, the residuals between model prediction and training data can be analysed for whiteness, e.g using residual autocorrelation (ACF), autoregressive model (AR), cumulative periodogram and partial auto-correlation functions [36].

Especially when multiple highly correlated parameters have to be estimated, the unique correlations between model and control variables (CV) or disturbances (D) can only be estimated accurately if the information content of the training and validation data is sufficiently high and the sensorand actuator-uncertainty (error in variables) is limited. When this is not the case, e.g. when the correlation between, and noise levels in the available system outputs are high; no suitable, reliable model can be generated from these observations. In that case, a new, (active) excitation experiment should be carried out, where series of forced, uncorrelated excitations are 
generated for each controllable input and disturbance (either as step, sinusoidal, pseudo-random binary sequence (PRBS) or other forcing functions within the bounds) and applied to the system, while the resulting system output is being measured $\mid 35]$. Data used for model identification should include samples from a variety of working conditions and excited frequencies, preferably obtained over multiple years and under different control conditions. These examples show that this data gathering process is not an easy task in occupied buildings.

\subsection{Model Identification}

One of the hardest aspects of MBCC implementation is the parameter estimation for a suitable model for the building and HVAC installation [37]. The algorithms used for MBCC can either be model-free or model based. This paper only focusses on the latter approach. A good overview of model free (measurement based) BM is presented by Wang et al.[38]. In the (model based) approach, typically a regression model with fixed order is fitted to the available measurement data. In the GB or White box (WB) approach, HVAC and building models are generated and simulated, using assumptions of expected (modelled) control strategy, parameter values and disturbances. Some parameter estimation methods rely on data-based statistics only, others on the model effectiveness during application.

There are four distinct methods of MIMO parameter estimation available $\mid 36$ :

- Probabilistic semi-physical modelling (PSPM) is an approach using maximization of the likelihood function, to estimate the parameters on a predefined, physical description of a stochastic process.

- Deterministic semi-physical modelling (DSPM) uses resistance capacitance network analogue to an electric circuit to describe the dynamics of a process.

- MPC relevant identification (MRI) is a method in which a multi-step ahead prediction error is minimised over the same horizon as used for the predictive control.

- Subspace identification (4SID) is a black box parameter estimation approach, which identifies the optimal model parameters in a purely statistical manner. 
Despite the possible high prediction accuracy of a well-identified, high order model, for most practical control and prediction purposes, it is infeasible (especially in real-time applications) to calculate or emulate based on the full model. For these applications, model order reduction techniques exist, to identify a simplified model based on the full model. For this, both balanced realisation calculations and ad-hoc procedures exist, as described by Del Barrio et al. [39] While excitation signal design, parameter estimation procedures and reduction techniques are crucial for obtaining accurate models, a detailed analysis and description of these aspects are beyond the scope of this paper.

\subsection{Data sources for parameter estimation}

Historically, often a heuristic method of trial and error was used to fit model prediction output to measurement data. With this, the model performance is very dependent on the skill and knowledge level of the modeller. An alternative method, based on statistics, is a Bayesian calibration such as the method developed by Kennedy and O'Hagan [40].

When using building and HVAC emulation software (such as Trnsys or Energyplus) for nation-wide, top-down BM, often generic WB-models of several typologies of exemplar, representative buildings are generated (for example naturally ventilated large cellular office, naturally ventilated open plan office, air conditioned office, etc.). These can be used to make (emulated) estimates on hourly energy use, when combined with realistic user behaviour and material properties of the used building materials [41, obtained through surveys or through reported aggregated energy use of that building typology.

In the case of active tests, a highly influential input variable is vigorously actuated (perturbed), typically with a step excitation or cyclic function) while the (dynamic or steady state) response of the other outputs is studied (again in assumed fault-free conditions). The second approach is sometimes integrated into BEMS as an additional redundancy check.

In this GB-method, assumed probability distributions are assigned to uncertain parameters and a Latin Hypercube sampling (LHS) is performed on this search space, resulting in a set of possible emulator models. The open-loop simulation output of these models is compared stochastically to the validation measurement-data of the real building, leading to the estimation of a set of model parameters, together with a quantification of their uncertainty. 
This tuning procedure is infeasible for more complex CCx-related tasks which may require high order, multivariate parameter models (especially dynamic models). In this case, a multi-step sensitivity analysis is more appropriate, given the (often stringent) limitation in training data: first, the dimensions of the evaluated parameter space should be reduced, by proposing a model structure and order with a set of states with low correlation. Subsequently, (only) the most influential parameters can be identified 42 43 .

\section{Models for Benchmarking (BM), Performance Estimation (PE) and Energy conserving opportunities identification (ECOI)}

\subsection{Requirements of BM,PE,ECO-ident models}

The purpose of both BM and ECOI, is to predict and increase insight in EPI-patterns (e.g. energy use) and reduce (or remove) information asymmetry and high transaction costs of retrofit analysis 44 . The underlying, often non-linear effects of occupant behaviour, sub-system operation and building management can be included in this manner. Occupant behaviour and building commissioning have been shown to be very influential on energy use, leading to a renewed emphasis on empirical validation of building models and operational efficiency measures 44 .

The function of a PE-model is to accurately predict integrated (summed) values of key performance indicators (KPIs), over a long prediction horizon. Therefore, especially the low frequency response of ECOI-models should be modelled well for this sub-domain. Model mismatch should be monitored closely (using cross-validation) and should be minimised during model identification 40 .

The temporal resolution (here: simulation time step) typically used for these models, can vary widely: in the minute range (1-15 minutes) for fast HVAC control loops, in the hour range (0.5-6 hours) for building-shell evaluation in light buildings and in the day range (0.5 -3 days) for heavy buildings. When considering coupling with ground water loops or ground heat exchangers, time constants on an even longer time scale of weeks (.5 4 weeks) should be considered as well [45]. The default temporal resolution for most ECOI studies is 1 hour. The prediction time horizon for ECOI models can vary from 24 hours to 30 years, depending on the studied ECO and considered evaluation period. The default prediction horizon is 1 year. 


\subsection{Implementations of BM, PE and ECOI models}

Since BM, PE and ECOI are widely implemented in office buildings around the world, it is impossible to include all existing implementations in a single table. Only a small, (according to the main author) representative subset of existing publications are presented in table 1, in a predefined format which highlights the variation in used BM implementation models over the last 20 years.

A long history of benchmark modelling methods and types is described at length by Huang and his colleagues [46]. More recently, Lord et al [47] performed a comparative qualitative review of building commissioning regulations in USA and Europe. They state that the lack of a framwork which requires a minimal inspection time on-site, is a key issue in the ability of enforcing BM models. Corry et al [48 advocate the use of a sematic web based approach to store, label and exchange data between the different stakeholders at different phases of the building use, to track and maintain performance over each building phase.

Several alternative classification schemes can be suggested, for example based on the building phase when $\mathrm{Cx}$ is being applied: design phase (e.g. Environmental assessment schemes such as LEED, BREEAM), commissioning phase (Building energy certification schemes, such as EPBD Ashrae bEQ, performance contracting) or refurbishment phase (whole building assessment tools -e.g. ESOL- or hierarchical assessment and diagnosis tools for auditing or re-commissioning, e.g. EARM-OAM).

The used grouping criterion 'Granularity and dynamics' (first column in summarizing table 1 is based on the amount of building and system dynamics captured in the models, ranging from static to dynamic on the one hand, and based on the granularity on the other hand: from subzonal, to single zone for the whole building, to multi-zone modeling of the building and HVAC system. Grouping according to these criteria allows a comparison over a range of model types and orders within the BM-subdomain.

Benchmarking typically has a relatively low investment cost (440 to $1315 €$ per building) and can give a first indication of which buildings may yield substantial energy savings $[49]$. This is in contrast to the slightly more complex ECO or PM models $\left(0.1\right.$ to $\left.5 € / \mathrm{m}^{2} / y\right)$, which require more training data (measurements or system information), that is more costly to obtain, but often results in more detailed insight into HVAC system performance. 


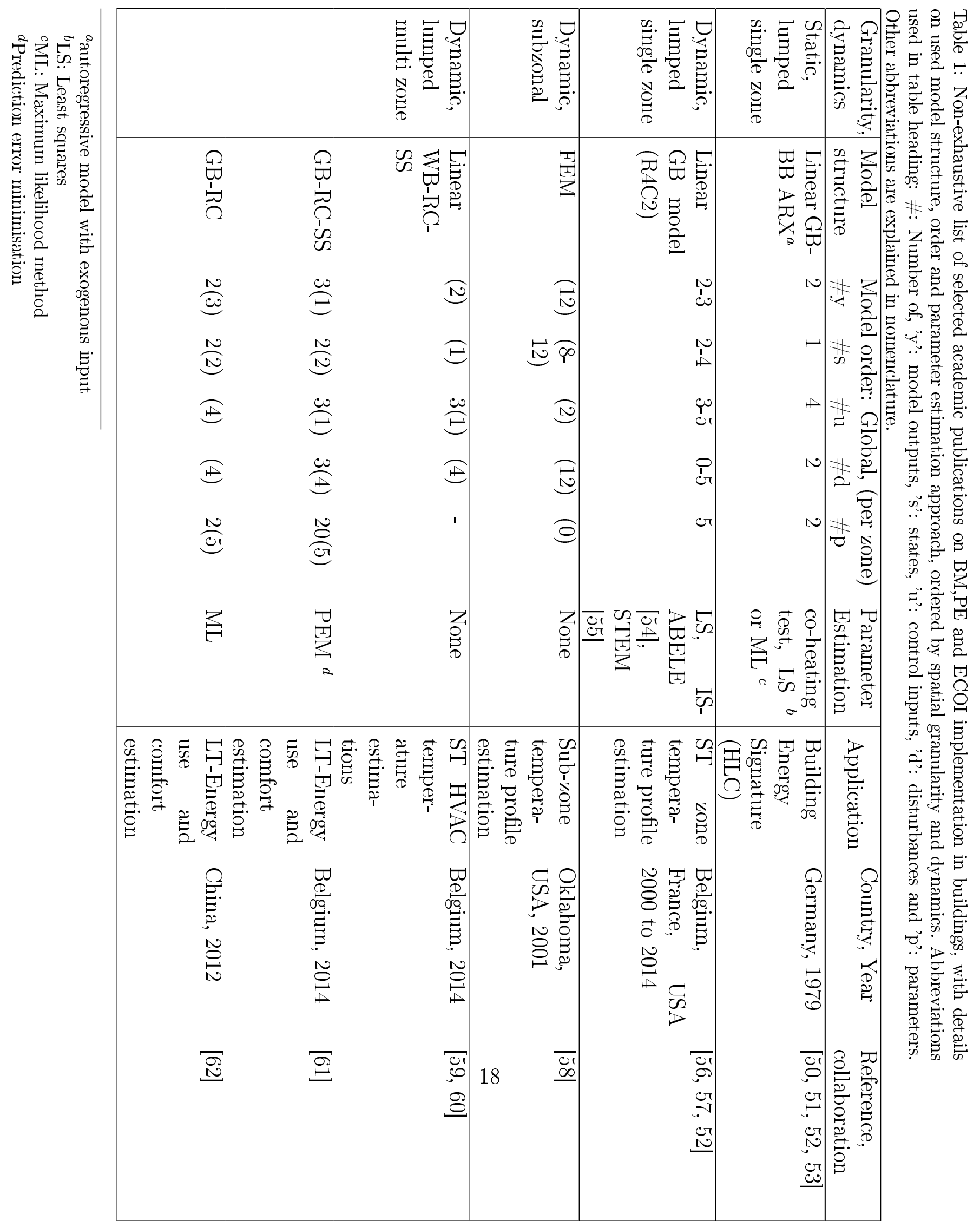




\section{Models for Fault detection, diagnosis and evaluation (FDDe)}

On model based FDDe, Katipamula 63 and Isermann 64 have performed thorough reviews of existing literature and technologies, while other researchers such as Burton [65 have described the trends in the last ten years. Under the supervision of the International Energy Agency (IEA), multiple joined research efforts were undertaken to develop and implement automated HVAC system FDD tools in real buildings, in the Energy in Buildings and Communities-programme (IEA-EBC), such as annexes 25 (1996), 34 (2002), 40 (2005) and 47 (2011) 65.

IEA Annex 34 [66 investigated twenty-six FDD tools that have been deployed in twenty real buildings. These prototypes were designed to detect faults in PID parameter settings, fan speed changes, inappropriate sensor location, erroneous wiring of a sensor, stuck control valve and VAV damper, false AHU hatch opening, in buildings throughout the world, e.g. in Japan, Germany, France, The Netherlands, UK and Switzerland. Bushby and Schein (2000-2006) performed FDDe analysis in seven buildings in the USA, on AHU \& VAV installations. They concluded that the main problems in air sided buildings are AHU control loop tuning, equipment degradation and sensor and actuator faults.

A more recent overview of this field was performed by Lazarova et al [67|. They summarized the FDDe-related efforts for smart buildings. The key problem areas for FDDe implementation in office buildings and commonly used data-based or expert-based identification methods are discussed. From a more practical viewpoint, Belfast [68 describes the technical, economical and operational barriers which inhibit wide-scale implementation of commercially available FDDe software. The cost and complexity of generating a building model and fault knowledge base applicable to a broad building stock diversity are mentioned as important bottlenecks.

Often, models used for FDDe are steady state evaluation models, which cannot differentiate faulty operation from fault-free but transient operation, and have to be combined with a steady state detector [69|. However, reduced order models, based on knowledge and expert rule-based approach (GBmodels) seem to be the most generic and commercially viable solution for FDDe in the short and medium term 65].

The most commonly used parameter estimation methods for FDDe methods, are ARX and ARMAX (Autoregressive-moving-average model with exogenous input). Statistical methods are often applied to derive more robust parameters for evaluation: for parameter estimation, a principal component 
analysis (PCA) method was presented by Namburu [70]. A combination of the model-based FDD (MBFDD) method with the support vector machine (SVM) method was applied by Liang $\mid 71$, and Cho et al. [72 using the transient analysis of residual patterns.

\subsection{Requirements for FDDe models}

Model quality criteria (and performance criteria) of FDDe for HVAC systems could include the following KPIs ( 66, 73, which are typically evaluated (for a reference building) with respect to the total number of (supervised) classifications in the data set:

- Detection speed and sensitivity: minimum detectable fault level, and speed of detection

- Classification accuracy and isolability: percentage of correctly diagnosed faults

- Type II error: percentage of false negatives (false alarms)

- Type I error: percentage of false positives (incorrect fault-free diagnoses)

- Adaptability: flexibility of tuning the sensitivity between Type I and Type II errors

- Data requirements: training data and operational data-exchange quantity and quality

- Computational requirements during model identification and for the FDDe algorithm

The typical temporal resolution (of the evaluation time step) used for these models can vary widely, but is often in the second to minute range (0.01-15 minutes) for HVAC installations FDDe and in the hour range (0.56 hours) for building-shell FDDe procedures. The (historic) time horizon taken into account by FDDe algorithms is often smaller than these in a PE model, and can vary from 1 minute to 6 hours (for HVAC FDDe), or between 1 day and 7 days (for building-shell FDDe), depending on the studied fault and procedure goal (only detection, or also classification and evaluation). 
4.2. Implementation examples of FDDe models

Table 2 gives an overview of some of the FDDe techniques applied in buildings, with focus on the structure of the used models and parameter estimation techniques. The classification (first column in summarizing table 2 is made based on the type of 'Diagnosed fault(s)'. Note that in the literature, especially papers originating from US researchers, most of the reported FDDe system implementations are investigating air based installations (e.g. AHU's, rooftop units, VAV-boxes, fans, fan coil units). Since the focus in this paper is broader, the number of air-based FDDe-references were limited in favour of an overview of implemented models on installations using other energy carriers, such as water-based and refrigerant-based HVAC-system FDDe implementations.

\section{Models for Model based control (MBC)}

In this section, the respective requirements, implementation examples and used parameter estimation procedures of MBC for HVAC-systems are described.

HVAC control is challenging, since the building, building use and HVAC system contain non-linear dynamics, time-varying system dynamics and setpoints, and time-varying disturbances. Moreover, the sensor data quality and quantity are often low, due to low sampling rates, low resolutions and low accuracies. Finally, there is a strong interaction between subsystems and often a unified supervisory control structure is lacking [80]. If a controller can take into account correct, prior knowledge about the response of the system to disturbances and control inputs, it will be able to control it more efficiently. Therefore, for improved (near-optimal) control, models can be utilised.

Kavgic et al. 81 describe nine office building characteristics which are beneficial for the applicability of MPC. Two traits were marked as essential for good MPC applicability: high thermal building mass or heat storage options, and high, variable internal and external gains) Also, four traits were classified as important. The latter include high ventilation rates, long periods of non-occupancy, broad control setpoint ranges and slow HVAC system dynamics.

\subsection{Requirements of $M B C$-models}

The main performance criterion for $\mathrm{MBC}$, which thus also serves as prime model quality criterion (MQC) for the associated MBC-models, is 


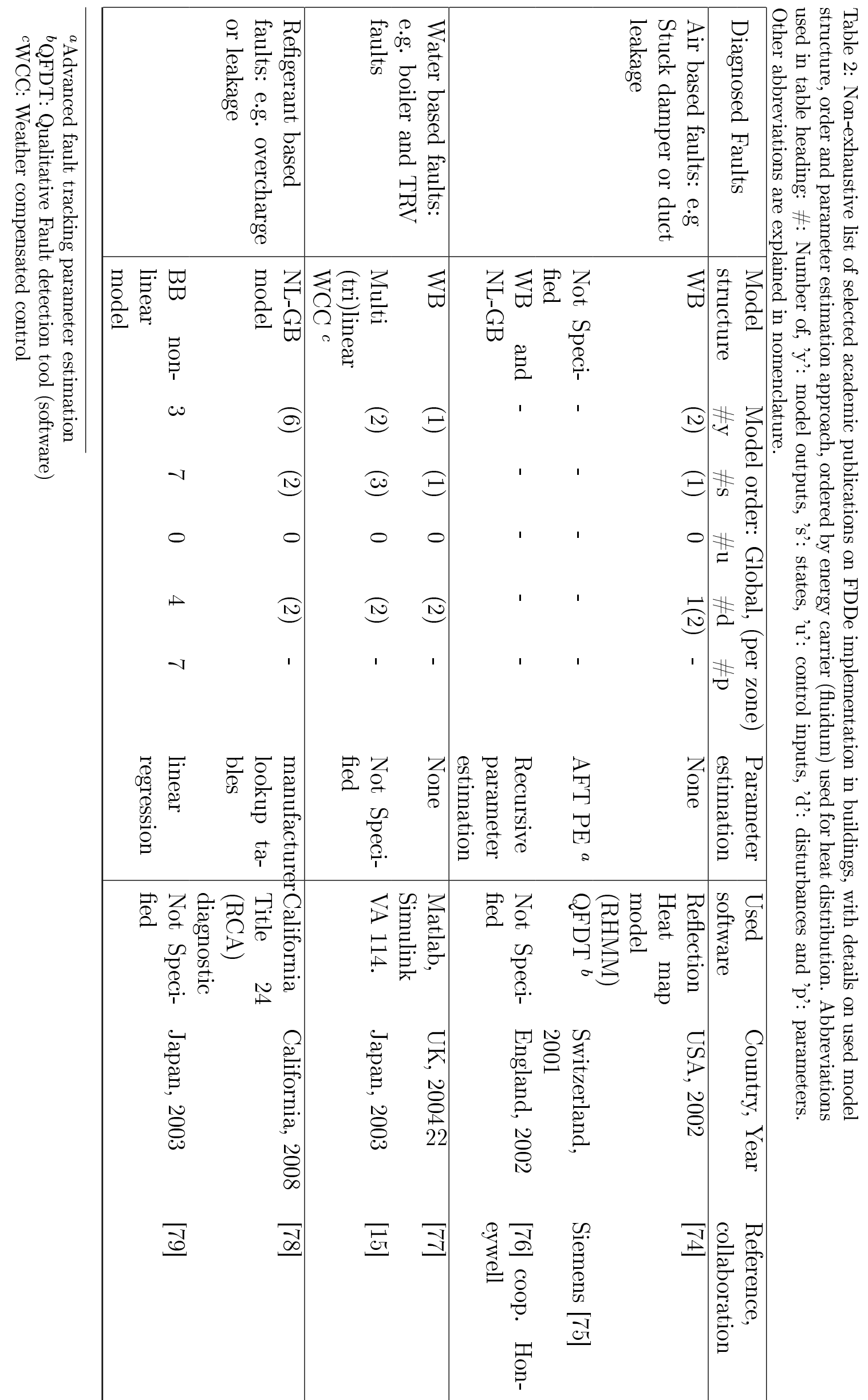


a good short-term (minutes to hours) system response prediction performance, and accurate state estimation at an appropriate temporal resolution [80]. The accuracy of long term predictions is less critical, especially for closed loop control.

For MPC, performance of the model over the prediction horizon is of main concern $[82$. This means that, for parameter estimation, the minimization of the prediction error over the prediction horizon will play a major role.

Furthermore, computational requirements are an important MQC for MBC-models. Typically, relatively large computational power is required to simulate optimal control paths for HVAC. An implemented MBC-controller needs access to (filtered) sensor data and needs to be able to modify actuator set points. This, among other aspects (such as controller model development) makes the implementation of a model based controller quite challenging. Also, it can be very time-consuming to identify a suitable control model.

The temporal resolution used for MBC control can vary widely. For building level or plant level temperature control, typically control time steps up to one hour are used $(0.2$ to $1 \mathrm{~h})$, since temperature is a slow moving process. For low level control (components), control time steps in the range of seconds to minutes ( 1 to $300 \mathrm{~s}$ ) are used. For control, three distinct time horizons are used: a 'backward time horizon' for state estimation, a 'control horizon', and a 'forward predictive horizon'. A typical MBC model is generated and estimated based on historical data from one or more seasons (3 months - 36 months). State estimations use a backward horizon of typically one day ( 24 hours), the control horizon of an MBC implementation, is typically 4 to $6 \mathrm{hrs}$, or up to the length of the control time step. The prediction horizon of a predictive MBC (aka. model predictive control, MPC) for building HVAC control is typically between 24 hours and 168 hours (one week), with a default value around 24 hours for light, and 48 hours for heavy buildings [80].

\subsection{Implementation examples of $M B C$-models}

HVAC control represents a broad field and a very mature market. Several millions of control loops (not all model based) are currently implemented around the world. Therefore, the purpose of this section, is not to give an exhaustive overview of this field, but to provide some insight in trends and common practices in the field and recurring themes in research efforts in this field, with a focus on the models and parameter estimation 
methods used. The focus in this review is on algorithms implemented in real case studies (buildings) only, see table 3

The classification used in the first column of table 3 describes whether the controller is implemented on room level (RL) (controlling terminal units), on plant level (PL) (controlling production, distribution and end units of one energy carrier) or building level (BL) model-based controllers (optimising production, distribution and terminal units of multiple energy carriers). Note that the goal of this table is to give an illustration of the variety in approaches to MBC-implementation, not to give an exhaustive overview of all implementations.

Many of the recent model-based control implementations for HVAC in offices involve model predictive control (MPC) $)^{8}$. Note that all reported implementation references are recent (less than five years old). Parallel to these realised and reported implementations, much research has and is being performed on MPC for HVAC-systems in office buildings, based on detailed building simulations [84, 80, 85], which have not (yet) been implemented into real-life controllers on real-life buildings.

\section{Discussion}

\section{Recurring model structures}

From the analysis of the cited references on MBCC implementations of MPC, BM, PE, ECO-ident and FDDe systems, it is clear that the MBCC technology in BEMS is a well-known and tested field in academic circles and is maturing in commercial BEMS-markets, but still has a very low level of penetration in commercial buildings. Most of the cited references in this paper were flagship applications or prestige projects, characterized by a large capital- and time-investment.

From the MB-BM implementation examples (see table 1), it can be seen that a low number of sensor inputs ( 1 to 5 ) is typically used and that the number of tracked states and outputs ( $\mathrm{s}$ and $\mathrm{y}$ ) in these models is relatively low (in contrast to MBC models or FDDe models). Confirming the conclusions deducted by Bertagnolio [19], table 1] shows that static single zone building models are typically implemented for BM, while they might be less applicable to ECOI. On the other hand, static multi-zone models

\footnotetext{
${ }^{8} \mathrm{MPC}$ is a general term for a suite of control strategies that selects control inputs via an online optimization of a predefined cost function at discrete time intervals, with explicit handling of input, output, and state constraints 83 .
} 


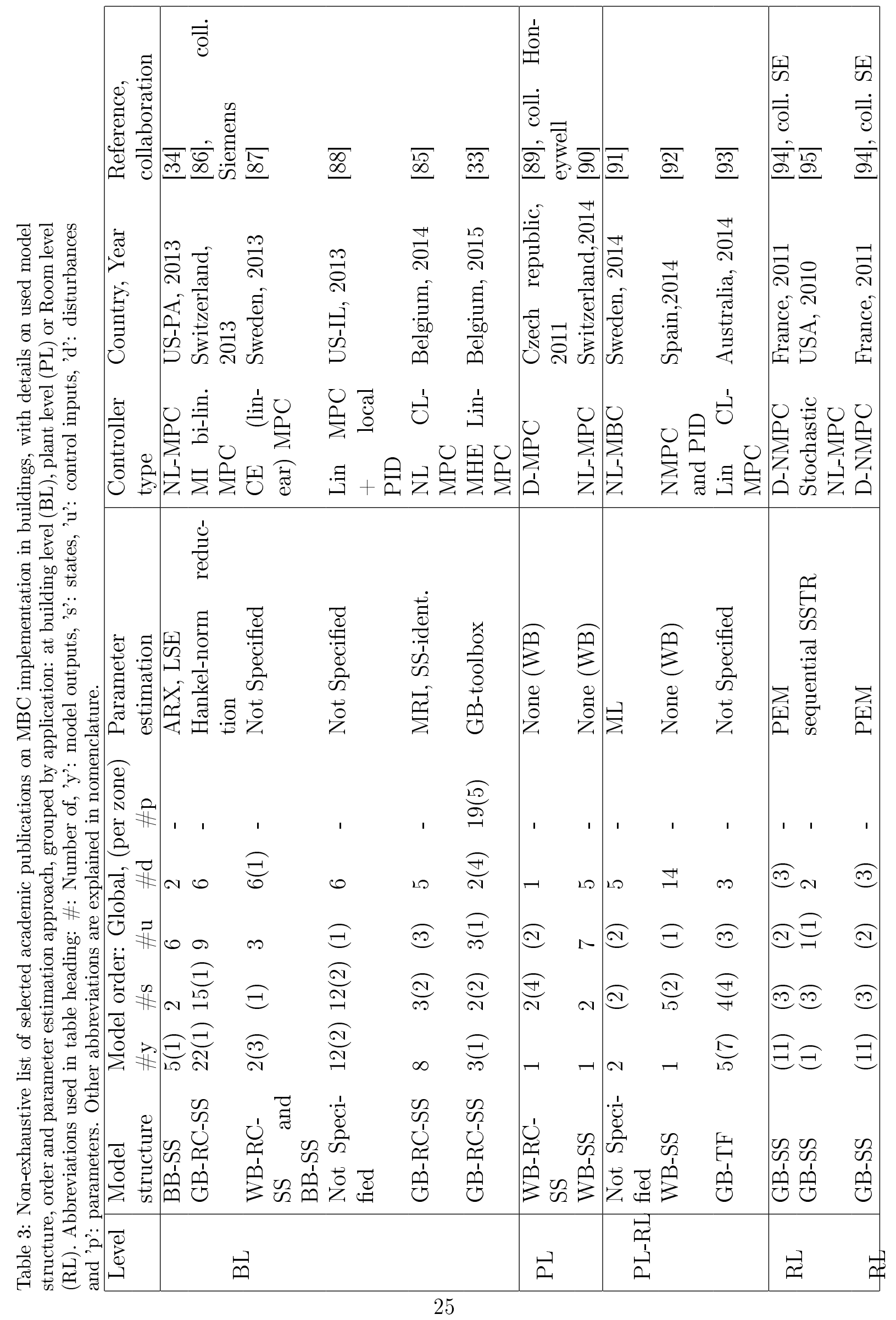


are applied for ECOI on building shell, but not on HVAC-installations. A dynamic single-zone model is appropriate for most ECOI and BM tasks, but not to evaluate multi-zone control, since it often gives bad estimates of annual heating \& cooling load. Lastly, dynamic multi-zone models can be very accurate for detailed ECOI, but require a large parameter estimation effort.

In most MB-BM-implementations, only one or two states are identified, calibrated and predicted. Moreover, since often only the summed (e.g. yearly) energy-values are critical for most PE applications, typically high level dynamics are ignored or simplified, leading to low(er) order, (more) simple evaluation models (in contrast to MBC models or FDDe models). On the other hand, quite a lot of tuning parameters are typically provided, to make accurate calibration with physically meaningful interpretations possible.

From the FDDe implementation examples (table 2), it is clear that a typical FDDe model, contrary to a BM model, has a large number of required measurement inputs (more than 5), and only one or few outputs to monitor (small y). Due to their large number of inputs, FDDe systems are typically deployed on component level (implemented by a single HVAC manufacturer), with optional communication of fault signals or information to upper (supervisory) levels. Also, some tuning parameters (p) may be included, to set (limit) the occurrence of type I and type II faults. A type I error (false positive) occurs when an FDDe-algorithm indicates a fault in the absence of it, whereas a type II error (undetected negative) occurs when a FDDe-algorithm fails to identify the occurrence of a fault $|96|$. To find a suitable FDDe model, a WB approach using domain knowledge only (without parameter estimation) is often applied, but also low order BB methods such as ARX appear frequently.

Both for the BM and FDDe implementation examples, it can be noted that quite a lot of parameters $(p)$ are used in the (GB or BB) models, to allow the accurate fitting of model output and building performance. The consequence of this observation is that much attention should be paid to correct parameter estimation, since an incorrect parameter can lead to a badly calibrated model, and thus degraded BM or FDDe performance. The ideal order (complexity, amount of parameters) of a PE model depends on the amount of system knowledge available and the uncertainty on the input parameters. A minimal model order is required to capture the relevant dynamics of the system. However, due to over-fitting, the prediction error 
in cross-validation also increases with model complexity from a certain point onwards. Also, the development cost and value for the user will vary based on chosen model complexity (and accuracy).

From the MBC implementation examples listed in table 3, it becomes clear that recently, the number of demonstration implementations for MPC has increased rapidly. Also, note the frequent collaboration of academia with industry, which indicates that the technology readiness level (TRL) is high already. Implementation in commercial products can be expected in the following years.

Regarding used models for MBC, a few observations can be made based on the reviewed literature. Firstly, in MBC implementations, most frequently low order models are used (low values for $\mathrm{x}$, typically 1 to 2 states per zone, 5 to 15 states in total). Secondly, a very small amount of actuated outputs (low values for y, typically between 1 and 3 ) is used. Thirdly, disturbance compensation is almost always implemented, either as an additional closed (PID) control loop after the MBC, or within the MBC controller itself (stochastic modelling of tracking error, feedback control, or receding horizon control). This shows that model mismatch has a considerable influence in real buildings. As a primary parameter estimation method, MPC-relevant identification is prevailing. This approach uses a multi-step ahead mismatch error minimisation.

\section{Data and calculation requirements for $M B C C$}

The diversity observed in tables 1, 2 and 3 indicates that the preferred model structure and parameter estimation method depend on other factors as well, beside the CCX-subdomain alone (BM, PE, ECOI, FDDe or MBC). The available input data and calculation power may have been taken into account for the choice of model structure, order and parameter estimation method. To investigate this assumption, the methods used in the investigated implementation examples are structured in a tree-based graph (figure 3, 4 and 5 for each sub-domain, describing the most frequently encountered model order, structure and parameter estimation procedure encountered for each combination of input data quality and calculation power.

From figure 3, in the case of BM, it can be seen that when limited data is available, especially low order black box methods are used in combination with ARMA or ARMAX parameter estimation methods. For most BM purposes, low order models are suitable, but the used model identification methods move to more complicated methods when calculation power or data is more abundant. 


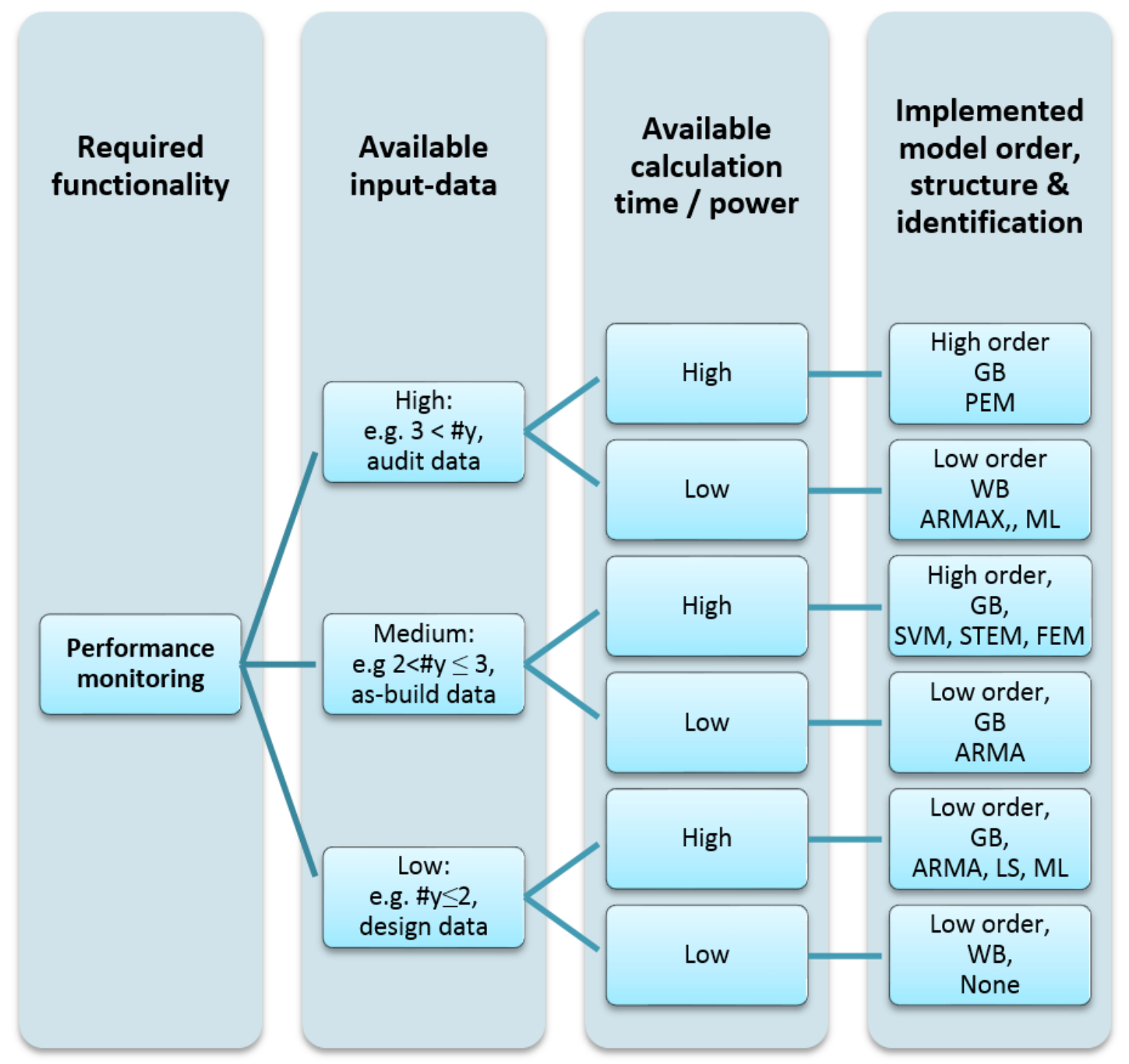

Figure 3: Model order, structure and parameter estimation procedure frequently encountered in implementations of BM, PE and ECO-ident, in relation to the availability of sensor data (high vs low quality,quantity) and calculation power (limited vs. abundant) 


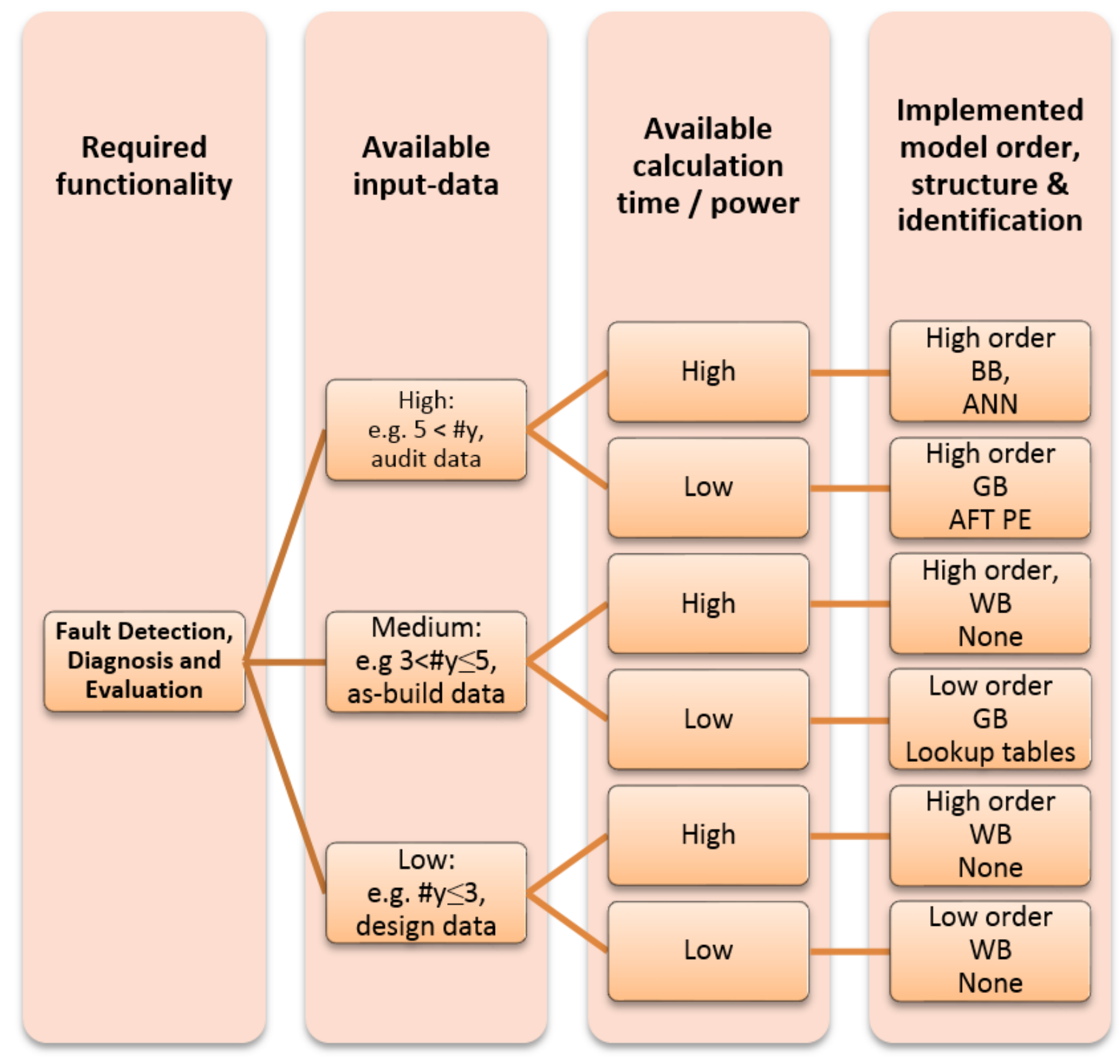

Figure 4: Model order, structure and parameter estimation procedure most frequently encountered in FDDe implementations, in relation to the availability of sensor data (high vs low quality, quantity) and calculation power (limited vs. abundant) 
In contrast to BM, figure 4 shows that for FDDe, most of the implemented models are higher order models. Especially GB and WB models are used. The tendency shifts to BB methods when input data is more abundant, while WB methods are prevalent when calculation time or input data is limited.

Lastly, when comparing used methods for MBC in relation to a qualitative estimate of available calculation power and data (see figure 5), it seems that low order models prevail at most levels (similar to the BM models), but the model structure is often WB or GB, since for control models, it is important that slight extrapolation does not distort from the physical response of the building. Also here, the used parameter estimation method is highly dependent on available calculation power and time, with a clear bias towards faster and less CPU-hungry parameter estimation methods when calculation power is limited.

\section{Multi-functional models}

Typically, the most accurate MBCC estimates can be attained with high calculation power (complex algorithms) and large (and highly accurate) input datasets. For control, near-optimal HVAC performance can be achieved with high-order model, moving horizon predictive control, augmented with low level PID-control. For PE, detailed calibrated GB model shows very accurate predictions, and for FDDe a calibrated WB model, built up from component level, shows good industrial scalability and accuracy.

However, a balanced trade-off should be made between required accuracy, optimality and investment costs. Calculation power and sensor requirement are critical factors. At component level, algorithms which require many sensor inputs but limited calculation power, are often available at low investment costs, while at upper (supervisory levels) calculation power is more affordable, but detailed and accurate sensor data may not be available.

Especially the few algorithms and parameter estimation procedures that can effectively harness this asymmetry, such as low order GB model with MPC relevant identification for supervisory control, and low order black box model with ARX identification, have a large implementation potential for (supervisory and distributed) MBCC.

Unfortunately, due to the differences in requirements and structures of the implemented models, the reuse potential for these models over multiple different MBCC domains is deemed limited. However, the sensor data, data acquisition, model identification procedures and modelling infrastructure 


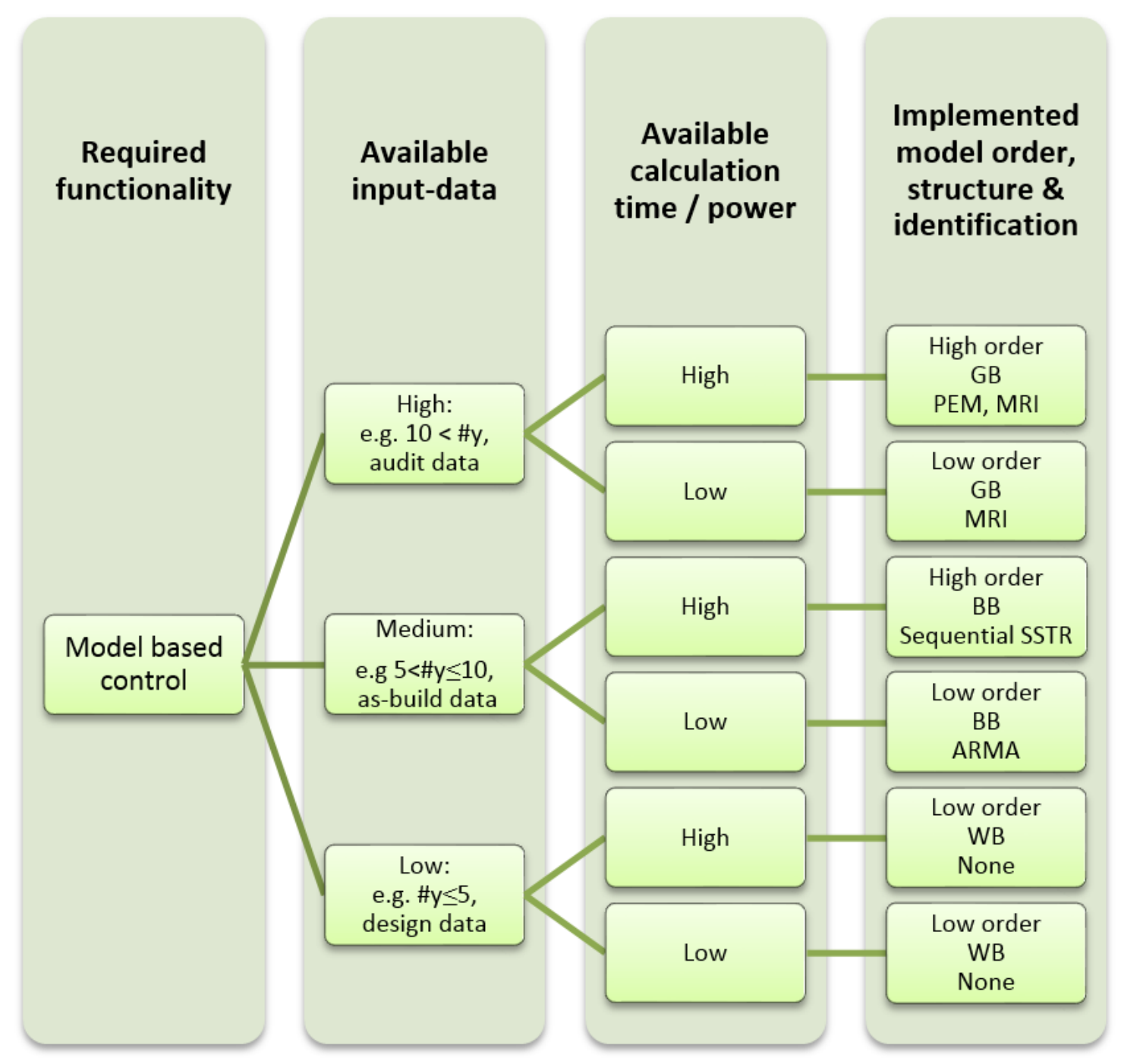

Figure 5: Model order, structure and parameter estimation procedure most frequently encountered in $\mathrm{MBC}$ implementations, in relation to the availability of sensor data (high vs. low quality, quantity) and calculation power (limited vs. abundant) 
can (and might) be shared readily between different MBCC sub-domains. For example, Project Haystack [97] is an initiative which supports clear labelling and data sharing between different HVAC-applications.

This sharing process may lead to economically viable and widespread MBCC implementations, which is actively supported by various organisations and ongoing initiatives in this field, such as IEA (Annex 63) [98].

While the development of a detailed building model often corresponds to a substantial investment cost, several academic authors $99,100,101,102$ claim and show that with the assistance of a detailed, well calibrated building simulation model, a wide range of system specifications and supervisory controller design alternatives can be evaluated (PM), improved during operation (FDDe) and optimized (MBC), despite uncertainty in inputs, outputs, disturbances and model mismatches.

\section{Conclusion}

A large diversity can be observed in used models and parameter estimation procedures for MBCC implementations in real buildings in multiple aspects: between the sub-domains, within one sub-domain based on available data and calculation power, and also between competing BEMS manufacturers and academic researchers.

A selection of a suitable model structure and parameter estimation method can be made for each MBCC domain. In this selection process, calculation power availability and sensor data accuracy have a large influence on expected MBCC performance and investment costs. Advisory decision trees have been constructed for this selection. At component level, algorithms which require many sensor inputs but limited calculation power, are likely to be economically feasible, while at upper (supervisory) levels, calculation power is more abundant, but detailed and accurate sensor data may not be readily available.

The reuse potential for models over multiple different MBCC sub-domains is shown to be limited, due to the wide variation in scope, performance criteria and used model structures. On the other hand, in most buildings the sensor data, data acquisition, parameter estimation procedures and modelling infrastructure can be shared well between different MBCC subdomains. Also, FDDe and BM tools can be integrated as enablers into on-going commissioning solutions to realise improved model-based control.

Moreover, there seems to be a consent on the importance of crucial model quality criteria for MBCCx-subdomains. To summarize, the most 
important MQC found for each of the domains is:

A: For benchmarking, performance evaluation and identification of ECOimpacts, the long term, integrated prediction performance

B: For fault detection and diagnosis, the medium term prediction performance

C: For improved model based control, a good short term emulation performance

Further research on the HVAC fault sensitivity of MBC (e.g. MPC), risk analysis of undetected building or HVAC faults (economic impact of undetected failures) and semi-automated GB-based PE methods could support the transition of (part of) the European building stock towards smarter buildings further, leading to more BEMS equipped with MBCC systems, carrying out (possibly model-based) MBC, PE and FDDe tasks. Also, distributed and agent-based MBCC, PE and FDDe algorithms may prove their effectivity, by combining insights from multiple $\mathrm{CCx}$-domains, e.g. by identifying component faults through their impact on global utility use, or realise near-optimal distributed control through measurement data exchange between agents in different HVAC-components. 
843 8. Nomenclature 


\begin{tabular}{|c|c|}
\hline Abbreviation & Explanation (part 1) \\
\hline AECf & Annual Energy Consumption Impact of a fault \\
\hline AFT & Accellerated failure time \\
\hline $\mathrm{AHU}$ & Air handling unit \\
\hline ARMAX & Autoregressive-moving-average model with exogenous input \\
\hline ARX & Autoregressive model with exogenous input \\
\hline $\mathrm{BB}$ & Black box \\
\hline bEQ & Building energy quotient-program (US) \\
\hline BREEAM & Building research establishment environmental assessment method (UK) \\
\hline BL & Building level controller implementation (multiple energy flows) \\
\hline $\mathrm{BM}$ & Benchmark \\
\hline $\mathrm{CCA}$ & Concrete core activation \\
\hline $\mathrm{Cx}$ & Commissioning \\
\hline $\mathrm{CCx}$ or $\mathrm{CC}$ & Continuous commissioning \\
\hline $\mathrm{CE}$ & Certainty Equivalence \\
\hline DD-AHU & double deck AHU (hot and cold supply air) \\
\hline DMPC & Distributed MPC \\
\hline EARM-OAM & Energy Assessment and Reporting Methodology-Office Assessment Method, \\
\hline $\mathrm{ECO}(\mathrm{s})$ & Energy conservation opportunity (opportunities) \\
\hline ECOI & Energy conservation opportunity identification \\
\hline EUI & Energy use intensity \\
\hline FCU & Fan coil unit \\
\hline FDDe & Fault detection, diagnosis and evaluation \\
\hline $\mathrm{fl}$ & Number of floors considered in implementation \\
\hline GB & Grey box \\
\hline HLC & Heat loss coefficient \\
\hline HMM & Heat map model \\
\hline HW & Hardware \\
\hline ISABELE & In-situ assessment of the building enveLope performances (EU project) \\
\hline KPI & Key performance indicator \\
\hline LEED & Leadership in Energy and Environmental design (US) \\
\hline $\mathrm{LS}$ & Least square error minimisation \\
\hline MI & Mixed integer \\
\hline MBCx & Model based commissioning \\
\hline $\mathrm{MBCC}$ & Model based Continuous commissioning \\
\hline MPC & Model predictive control \\
\hline
\end{tabular}




\begin{tabular}{|c|c|}
\hline Abbreviation & Explanation (part 2) \\
\hline MTTF & mean time to failure \\
\hline $\mathrm{MQC}$ & model quality criterion \\
\hline ML & Machine Learning \\
\hline ML & Maximum likelihood (method) \\
\hline MLE & Maximum likelihood estimation \\
\hline MRI & (Multi-step prediction) MPC relevant identification \\
\hline NMPC & Non linear MPC \\
\hline PL & Plant level controller implementation (one energy carrier) \\
\hline RAD & Radiative terminal unit (radiator or convector) \\
\hline $\mathrm{RC}$ & Resistive-capacitive analogy \\
\hline PE & Performance Evaluation \\
\hline PEM & Prediction error minimisation \\
\hline $\mathrm{RL}$ & Room level controller implementation \\
\hline RMSE & Root mean Square error \\
\hline SCOP & Seasonal coefficient of performance \\
\hline $\mathrm{SE}$ & Schneider Electric \\
\hline SEER & Seasonal energy efficiency ratio \\
\hline $\mathrm{SD}-\mathrm{AHU}$ & Single duct AHU (only one supply duct) \\
\hline Sota & State of the art \\
\hline SS & State space \\
\hline SSTR & subspace trust region solve \\
\hline STEM & Short Term Energy Monitoring \\
\hline SW & Software \\
\hline TABS & Thermally active building system \\
\hline TB & Toolbox \\
\hline TRL & Technology readiness level \\
\hline WB & White box \\
\hline WBM & whole building model \\
\hline $\mathrm{WCC}$ & Weather compensated control \\
\hline QFDT & Qualitative Fault Detection Tool (commercial software) \\
\hline$\# \mathrm{z}$ & Number of zones considered in implementation \\
\hline$\# \mathrm{y}$ & Number of considered observations (measurements, inputs) \\
\hline$\# \mathrm{x}$ & Number of controlled states \\
\hline$\# \mathrm{u}$ & Number of controlled input signals \\
\hline$\# \mathrm{~d}$ & Number of considered disturbances \\
\hline$\# \mathrm{p}$ & Number of estimated parameters \\
\hline
\end{tabular}




\section{References}

[1] I. Knight. iSERVcmb project: Inspection of HVAC systems through continuous monitoring and benchmarking. 2013. URL: http://www. iservcmb.info/

[2] BPIE. Building performance Institue Europe Data Hub. accessed on 26/06/2015. 2015. URL: http://bpie.eu/data_hub.html.

[3] A. Boyano, P. Hernandez, and O. Wolf. "Energy demands and potential savings in European office buildings: Case studies based on EnergyPlus simulations". In: Energy and Buildings 65.0 (2013), pp. 19 -28. ISSN: 0378-7788. DOI: http : / / dx .doi . org/10 .1016/ j . enbuild.2013.05.039, URL: http://www . sciencedirect .com/ science/article/pii/S0378778813003277.

[4] E. Mils. The cost-effectiveness of commercial-buildings commissioning: A meta-analysis of energy and non-energy impacts in existing buildings and new construction in the United States (LBNL-56637). 2004. URL: http://www.des.wa.gov/SiteCollectionDocuments/ Facilities/Energy/Commissioning/Cx_Cost\%20Effectiveness . pdf.

[5] T.A. Reddy and D.E. Claridge. "Using synthetic data to evaluate multiple regression and principal component analyses for statistical modeling of daily building energy consumption". In: Energy and Buildings 21.1 (1994), pp. 35 -44. ISSN: 0378-7788. DOI: http://dx. doi . org/10.1016/0378-7788(94) 90014-0, URL: http : //www . sciencedirect.com/science/article/pii/0378778894900140.

[6] K.W. Roth et al. "The Energy Impact of Commercial Building Controls and Performance Diagnostics: Market Characterization, Energy Impact of Building Faults and Energy Savings Potential". In: DOE report, by TIAX LLC (2005). http://docs.lib.purdue.edu/cgi/viewcontent.cgi?article=166

[7] E. Mils. "Building commissioning: a golden opportunity for reducing energy costs and greenhouse gas emissions in the United States". In: Energy Efficiency 4.4 (2009), pp. 145-173. DOI: $10.1007 / \mathrm{s} 12053-$ 011-9116-8.

[8] L. Luskay, M. Brambley, and Katipamula S. Methods for automated and continuous commissioning of building systems. April. 2003. URL: http://www.osti.gov/scitech/biblio/810800. 
[9] Haorong Li and James E Braun. "An overall performance index for characterizing the economic impact of faults in direct expansion cooling equipment. Valuation de la performance utilise afin de Grille globale de riser lâĂŹimpact economique des pannes survenant dans les carac". In: International journal of Refrigeration 30 (2007). DOI: 10.1016/j.ijrefrig.2006.07.026.

[10] IEA Energy conservation in Buildings. IEA Annex 34: Computer Aided Evaluation of HVAC System Performance. Birmingham: FaberMaunsell Ltd Marlborough House. ISBN: 9780954660017.

[11] Michae Eardley. "An engineered approach to ongoing commissioning". In: Consulting - Specifying Engineer 1.4 (2016), p. 1. DOI: isbn08925046.

[12] IEA Energy conservation in Buildings. IEA Annex 40: Building Commissioning to Improve Energy Performance. Birmingham: FaberMaunsell Ltd Hertfordshire United Kingdom.

[13] Inc. Portland Energy Conservation et al. State-of-the-Art Review for Commissioning Low Energy Buildings: Existing Cost/Benefit and Persistence Methodologies and Data, State of Development of Automated Tools and Assessment of Needs for Commissioning ZEB. Birmingham.

[14] P. Torcellini et al. "DOE Commercial Building Benchmark Models". In: Proceedings of the 2008 ACEEE Summer study on Energy Efficiency in buildings -.- (2008), pp. -. URL: http://www.nrel.gov/ docs/fy080sti/43291.pdf

[15] Wang F. and Yoshida H. "A continuous commissioning tool based on simulation and operation". In: 2003. URL: http: //www.inive.org/ members_area/medias/pdf/Inive/IBPSA/UFSC82 .pdf (visited on $03 / 31 / 2015)$.

[16] ASHRAE. "ASHRAE Guideline 1-1996: The HVAC Commissioning Process". In: (1996), pp. 1-48.

[17] ASHRAE. "ASHRAE Guideline 0-2013: The Commissioning Process". In: (2013).

[18] K. W. Roth et al. "Advanced Controls for Commercial Buildings: Barriers and Energy Savings Potential". en. In: (July 2009). URL: http://www . tandf online.com.kuleuven .ezproxy . kuleuven . be/ doi/abs/10.1080/01998590609509479\\#.VKpsDHsueAg. 
[19] S Bertagnolio. "Evidence-Based Model Calibration for Efficient Building Energy Services". In: June (2012). URL: http: // orbi.ulg .ac . be/handle/2268/125650.

[20] C. Bogen. "Building Automation Modeling information exchange (BAMie)". In: buildingSMART alliance, National Institute of building Sciences, Washington, DC (2012). URL: availableonline, athttp: //www.nibs.org/?page=bsa_bamie.

[21] M. Liu et al. "Continuous Commissioning Leading Energy Project Process-An Industry Approach". In: Proceedings of the Fifth International Conference for Enhanced Building Operations, Pittsburgh, Pennsylvania (2005). URL: http : / / digitalcommons . unl . edu / archengfacpub/30/.

[22] T. Bailey and Zheng O. Neill. "Automated Continuous Commissioning of Commercial Buildings, ESTCP Project EW-200929". In: September (2011). URL: http://simulationresearch . lbl .gov/ sites/all/files/bailey-lbnl-5734e.pdf.

[23] S. Wang and Z. Ma. "Supervisory and Optimal Control of Building HVAC Systems : A Review Supervisory and Optimal Control of Building HVAC Systems : A Review". In: HVAC and R Research 14.1 (2011), pp. 37-41.

[24] D. Choiniere and N. Milesi-Ferretti. Project summary report. International Energy Agency, ECBCS, 2006, p. 60.

[25] EVO. International Performance Measurement and Verification Protocol, Concepts and Options for Determining Energy and Water Savings. Ed. by Efficiency Valuation Organization. Vol. 3. 2007.

[26] ASHRAE. ASHRAE Guideline 14-2015: Measurement of Energy, Demand and Water Savings. Ed. by American Society of HRVAC Engineers. 2015.

[27] L. Webster and J. Bradford. M\& V Guidelines: Measurement and verification for federal energy projects, version 3.0. accessed on 15/05/2015. 2008. URL: http : / / energy - gov / eere / femp / downloads / mv guidelines-measurement-and-verification-federal-energyprojects-version-30. 
[28] M. Effinger, J. Anthony, and L. Webster. "Case studies in using whole building interval data to determine annualized electrical savings". In: Ninth International Conference for Enhanced Building Operations, Austin, Texas (2009). URL: http://repository.tamu.edu.

[29] I. Mezic and T. Runolfsson. "Uncertainty propagation in dynamical systems". In: Automatica 44.12 (Dec. 2008), pp. 3003-3013. ISSN: 00051098. DOI: $10.1016 / \mathrm{j}$.automatica.2008.04.020. URL: http: //linkinghub.elsevier.com/retrieve/pii/S0005109808002914

[30] M. Gruber. Energy efficient indoor climate control - A practical approach for enhanced implementability. Doktorsavhandlingar vid Chalmers tekniska hogskola. Chalmers tekniska hogskola, 2014. ISBN: 978-91-7597-105-6. URL: availableonlineathttp://publications. lib.chalmers.se/records/fulltext/164192/164192.pdf.

[31] Reddy A. Evaluation and Assessment of Fault Detection And Diagnostic Methods for Centrifugal Chillers - II. 2006.

[32] F. P. Lopez et al. "Experimental analysis and model validation of an opaque ventilated facade". In: Building and Environment 56 (2012), pp. 265 -275. ISSN: 0360-1323. DOI: http://dx.doi.org/10.1016/ j . buildenv . 2012 .03.017. URL: http: / / www . sciencedirect . com/science/article/pii/S0360132312001096.

[33] R. De Coninck and L. Helsen. "Quantification of Flexibility in Buildings by Cost Curves - Methodology and Application". In: Applied Energy (accepted) (2015).

[34] Pengfei Li, ZD O'Neill, and JE Braun. "Development of ControlOriented Models for Model Predictive Control in Buildings." In: ASHRAE Transactions (2013). URL: http://www.ibpsa.us/presen-ations / 2013.06\_IBO\_Boulder/Friday/ModelingandDesignforOperationsII/ ModelingforDesignandOperationsII \_PengfeiLi\_ZhengONeill. pdf.

[35] P. Bacher and H. Madsen. "Identifying suitable models for the heat dynamics of buildings". In: Energy and buildings 43.43 (2011), pp. 15111522. DOI: $10.1016 / \mathrm{j}$.enbuild.2011.02.005.

[36] S. Privara et al. "Building modeling: Selection of the most appropriate model for predictive control". In: Energy and Buildings 55.0 (2012), pp. 341 -350. ISSN: 0378-7788. DOI: http://dx.doi.org/10. 
1016/j.enbuild.2012.08.040. URL: http://www.sciencedirect. com/science/article/pii/S0378778812004446.

[37] Fumo N., Mago P., and Luck P. "Methodology to estimate building energy consumption using EnergyPlus Benchmark Models". In: Energy and Buildings 42.12 (2010), pp. 2331 -2337. ISSN: 0378-7788. DOI: http://dx.doi .org/10.1016/j . enbuild . 2010.07.027. URL: http://www. sciencedirect.com/science/article/pii/ S0378778810002574.

[38] S. Wang, C. Yan, and F. Xiao. "Quantitative energy performance assessment methods for existing buildings". In: Energy and Buildings 55.0 (2012). Cool Roofs, Cool Pavements, Cool Cities, and Cool World, pp. 873 -888. ISSN: 0378-7788. DOI: http://dx.doi.org/10. 1016/j.enbuild.2012.08.037. URL: http://www.sciencedirect. com/science/article/pii/S0378778812004410.

[39] P. Behar E. P. Del Barrio G. Lefebvre and N. Bailly. "Using model size reduction techniques for thermal control applications in buildings". In: Energy and Buildings 33.1 (2000), pp. 1-14.

[40] Y. Heo, R. Choudhary, and G.A. Augenbroe. "Calibration of building energy models for retrofit analysis under uncertainty". In: Energy and Buildings 47 (Apr. 2012), pp. 550-560. ISSN: 03787788. DOI: 10.1016/j . enbuild .2011.12.029. URL: http:// linkinghub. elsevier.com/retrieve/pii/S037877881100644X.

[41] E. Fabrizio, D. Guglielmino, and V. Monetti. "Italian benchmark building models: The office building". In: Proceedings of Building Simulation 2011: 12th Conference of International Building Performance Simulation Association 1.1639 (2011), pp. 1981-1988. URL: http://www .ibpsa.org/proceedings/BS2011/P_1639.pdf.

[42] T.A. Reddy, I. Maor, and C. Panjapornpon. "Calibrating detailed building energy simulation programs with measured data-part I: general methodology (RP-1051)". In: HVAC and R Research 13.2 (2007), pp. $221-241$.

[43] J.S. Haberl and C.H. Culp. "Review of methods for measuring and verifying savings from energy conservation retrofits to existing buildings". In: Energy and Buildings (2005). Energy Systems Laboratory Report ESL-TR-03/09-01. 
[44] D. Hsu. "Improving energy benchmarking with self-reported data". In: Building Research and Information 42.5 (2014), pp. 641-651. DOI: 10.1080/09613218.2014.887612

[45] M. Sourbron and C. Verhelst. "Building models for Model Predictive Control of office buildings with Concrete Core Activation". In: Journal of Building (2011). DOI: 10.1080/19401493.2012.680497. URL: http://scholar.google.com/scholar?hl=en \\&btnG=Search \\&q= intitle: Building+models+for+Model+Predictive+Control+of+ office+buildings+with+Concrete+Core+Activation $\backslash \# 0$.

[46] J. Huang et al. 481 Prototypical Commercial Buildings for 20 Urban Market Areas. 1991.

[47] Sue-Fay Lord et al. "Comparative review of building commissioning regulation: a quality perspective". In: Building Research Information 44.5-6 (2016), pp. 630-643. ISSN: 0961-3218. DOI: 10.1080/ 09613218 . 2016 .1181955. URL: http: //www . tandf online . com/ doi/full/10.1080/09613218.2016.1181955.

[48] Edward Corry et al. "A performance assessment ontology for the environmental and energy management of buildings". In: Automation in Construction 57 (2015), pp. 249-259. ISSN: 09265805. DOI: 10 . 1016/j.autcon.2015.05.002.

[49] O.T. Masoso and L.J. Grobler. "The dark side of occupantsâĂŹ behaviour on building energy use". In: Energy and Buildings 42.2 (2010), pp. 173-177.

[50] R. Sonderegger and M. Modera. "Electric co-heating: a method for evaluating seasonal heating efficiencies and heat loss rates in dwellings". In: Proceedings of Second CIB Symposium on Energy Conservation in the Built Environment (1979).

[51] G. Bauwens and S. Roels. "Co-heating test: A state-of-the-art". In: Energy and Buildings 82.0 (2014), pp. 163 -172. ISSN: 0378-7788. DOI: http://dx.doi.org/10.1016/j . enbuild . 2014.04.039. URL: http:// www . sciencedirect . com/science/article/pii/ S0378778814003648

[52] R. Staf. IEA EBC ANNEX 58: Reliable Building Energy Performance Characterisation Based on Full Scale Dynamic Measurements. accessed on 15/05/2015. 2015. URL: http : // www . ecbcs . org / annexes/annex58.htm. 
[53] C. Ghiaus. "Experimental estimation of building energy performance by robust regression". In: Energy and Buildings 38.6 (2006), pp. 582 -587. ISSN: 0378-7788. DOI: http : / / dx .doi .org/10.1016/ j . enbuild.2005.08.014. URL: http://www.sciencedirect.com/ science/article/pii/S0378778805001799.

[54] Boisson P. and Schetelat P. "ISABELE method: In-Situ Assessment of the Building EnveLope pErformances". In: 2014. URL: http:// www . ssb2014 . ulg . ac . be / uploads / SSB2014_Program_v1 . pdf (visited on 12/10/2014).

[55] R. Judkoff et al. Side-by-Side Thermal Tests of Modular Offices: A Validation Study of the STEM Method. 2000. URL: Availableonline, athttp://www.nrel.gov/docs/fy010sti/23940.pdf.

[56] G. Flamant g. Lethe P. Steskens and B. Meurisse. "An adapted coheating test and experimental infrastructure for thermal dynamic response and performance identification of residential buildings". In: Proceedings of the 9th conference on System simulation in buildings 20141.9 (2014), pp. 388-407. URL: http://ssb2014.ulg.ac.be/.

[57] I. Heusler M. C. Kersken and P. Strachan. "Full scale empirical validation for building energy simulation programs". In: Proceedings of the 9th conference on System simulation in buildings 20141.9 (2014), pp. 1981-1988. URL: http://ssb2014.ulg.ac.be/.

[58] S.J Rees and P Haves. "A nodal model for displacement ventilation and chilled ceiling systems in office spaces". In: Building and Environment 36.6 (2001). Building and Environmental Performance Simulation:Current State and Future Issues, pp. 753 -762. ISSN: 0360-1323. DOI: http : / /dx .doi .org/10 .1016/S0360 - 1323(00) 00067-6. URL: http://www . sciencedirect . com/science/article/pii / S0360132300000676.

[59] E. Janssen et al. Thermal Grid: A novel ring-shaped HVAC distribution layout (Report in Dutch). 2013. URL: http://kce.thomasmore. be/thermal-grid/.

[60] L. Peeters et al. "Control of Heating systems in residential buildings: current practice". In: Energy and Buildings 40.1 (2008), pp. 14461455. ISSN: unknown. 
[61] R. De Coninck et al. "Toolbox for development and validation of grey-box building models for forecasting and control". In: Journal of Building Performance Simulation (accepted) 0.0 (2015), pp. 116. DOI: $10.1080 / 19401493$. 2015 . 1046933, URL: http : / / www . tandfonline.com/action/showCitFormats?doi=10.1080\%2F19401493. 2015.1046933.

[62] H.J. Chen, D.W.P. Wang, and S.L. Chen. "Balancing adjustment of exhaust duct system using feedback simulation method". In: $A p$ plied thermal engineering 26.5-6 (2006), pp. 463-470. URL: http:// linkinghub.elsevier.com/retrieve/pii/S1359431105002826.

[63] S. Katipamula and M. Brambley. "Review Article: Methods for Fault Detection, Diagnostics, and Prognostics for Building SystemsâĂŤA Review, Part II". In: HVAC\&R Research 11.2 (Apr. 2005), pp. 169187. ISSN: $1078-9669$. DOI: $10.1080 / 10789669.2005 .10391133$, URL: http://www.tandfonline.com/doi/abs/10.1080/10789669. 2005.10391133.

[64] R. Isermann. "Model-based fault-detection and diagnosis âĂS status and applications". In: Annual Reviews in Control 29.1 (2005), pp. 71-85. ISSN: 13675788. DOI: $10.1016 / \mathrm{j}$.arcontrol. 2004.12 . 002. URL: http:// linkinghub . elsevier .com/retrieve/pii / S1367578805000052.

[65] Ken Bruton et al. "Review of automated fault detection and diagnostic tools in air handling units". English. In: Energy Efficiency 7.2 (2014), pp. 335-351. ISSN: 1570-646X. DOI: 10.1007/s12053-0139238-2. URL: http://dx.doi.org/10.1007/s12053-013-9238-2.

[66] A. Dexter. Technical Synthesis Report annex 34: Computer Aided Evaluation of HVAC System Performance (annex 34). available for download at http://www.iea-ebc.org/projects/completed-projects/ebcannex-34/. 2006, p. 60.

[67] Sanja Lazarova-Molnar et al. "Fault detection and diagnosis for smart buildings: State of the art, trends and challenges". In: 2016 3rd MEC International Conference on Big Data and Smart City (ICBDSC). IEEE, 2016, pp. 1-7. ISBN: 978-1-5090-1365-4. DOI: 10.1109/ICBDSC. 2016.7460392. URL: http://ieeexplore . ieee.org/document/ $7460392 /$. 
[68] Janine Belfast. "Fault Diagnostics Tools for Commercial BuildingsâĂŤApplications, Algorithms and Barriers". In: Energy Engineering 111.3 (2014), pp. 57-78. ISSN: 15460118. DOI: 10.1080/01998595.2014. 10816367. URL: http://www.tandfonline.com/doi/abs/10.1080/ 01998595.2014 .10816367$.

[69] D. A. Veronica. "Automatically detecting faulty regulation in HVAC controls". In: HVACER Research 19.4 (2013), pp. 412-422. URL: http : / / www . tandf online . com . kuleuven . ezproxy . kuleuven . $\mathrm{be} / \mathrm{doi} / \mathrm{pdf} / 10.1080 / 10789669.2013 .789369$.

[70] S. M. Namburu et al. "Data-Driven Modeling, Fault Diagnosis and Optimal Sensor Selection for HVAC Chillers". In: IEEE Transactions on Automation Science and Engineering 4.3 (July 2007), pp. 469473. ISSN: 1545-5955. DOI: 10 . 1109/TASE . 2006 . 888053. URL: http : / / ieeexplore . ieee .org / lpdocs / epic03/wrapper.htm? arnumber $=4266818$.

[71] J. Liang and R. Du. "Model-based Fault Detection and Diagnosis of HVAC systems using Support Vector Machine method". In: International Journal of Refrigeration 30.6 (Sept. 2007), pp. 11041114. ISSN: 01407007. DOI: $10.1016 / \mathrm{j}$. ijrefrig. 2006.12 .012 . URL: http : / / ww . sciencedirect.com/science/article/pii/ S0140700707000072.

[72] S.-H. Cho et al. "Transient pattern analysis for fault detection and diagnosis of $\{\mathrm{HVAC}\}$ systems". In: Energy Conversion and Management 46.18âĂŞ19 (2005), pp. 3103 -3116. ISSN: 0196-8904. DOI: http : / / dx . doi .org / 10 .1016/ j . enconman . 2005.02 . 012 . URL: http: / / www . sciencedirect . com/science/article/pii / S0196890405000555.

[73] Y. Yu, D. Woradechjumroen, and D. Yu. "A review of fault detection and diagnosis methodologies on air-handling units". In: Energy and Buildings 82.0 (2014), pp. 550 -562. ISSN: 0378-7788. DOI: http:// dx.doi.org/10.1016/j.enbuild.2014.06.042. URL: http://www . sciencedirect.com/science/article/pii/S0378778814005246.

[74] G. Zimmermann, Y. Lu, and G. Lo. "A simulation based fault diagnosis strategy using extended heat flow models (HFM)". In: Proceedings of Building Simulation 201112 (2011), pp. 405-412. 
[75] A. Dexter and J. Pakanen. "Demonstrating Automated Fault Detection and Diagnosis Methods in Real Buildings". In: Proceedings of VTT Symposium: 217 (2011). Available online at http://www.ieaebc.org/projects/completed-projects/ebc-annex-34/, pp. 1-381.

[76] Norford L.K. "Demonstration of fault detection and diagnosis methods for air-handling units". In: HVACER research 8.1 (2002), pp. 4171. URL:https://dspace.lboro.ac.uk/dspace-jspui/bitstream/ 2134/3721/1/2813\%5B1\%5D.pdf.

[77] Z Liao and AL Dexter. "The potential for energy saving in heating systems through improving boiler controls". In: Energy and buildings 36.3 (2004), pp. 261-271. DOI: $10.1016 /$ j. enbuild.2003.12.006. URL: http:// www . sciencedirect . com/science/article/pii/ S0378778804000106

[78] J. Braun et al. A method for evaluating diagnostic protocols for packaged air conditioning equipment. 2012. URL: http://newbuildings . org/sites/default/files/FDD_Evaluator_Report_withAppendices . pdf.

[79] F. Xiao, C. Zheng, and S. Wang. "A fault detection and diagnosis strategy with enhanced sensitivity for centrifugal chillers". In: Applied Thermal Engineering 31.17-18 (Dec. 2011), pp. 3963-3970. ISSN: 13594311. DOI: $10.1016 / \mathrm{j}$. applthermaleng . 2011.07.047. URL: http:// www . sciencedirect . com/science/article/pii/ S1359431111004078.

[80] A. Afram and F. Janabi-Sharifi. "Theory and applications of $\{$ HVAC $\}$ control systems âĂ A review of model predictive control (MPC)". In: Building and Environment 72.0 (2014), pp. 343 -355. ISSN: 03601323. DOI: http://dx.doi.org/10.1016/j.buildenv . 2013.11. 016. URL: http://www. sciencedirect.com/science/article/ pii/S0360132313003363.

[81] Miroslava Kavgic, Trent Hilliard, and Lukas Swan. "Opportunities for Implementation of MPC in Commercial Buildings". In: Energy Procedia 78 (2015), pp. 2148-2153. ISSN: 18766102. DOI: 10.1016/ j.egypro.2015.11.300.

[82] S. Privara. "Building modeling and identification for predictive control". CTU, 2013, pp. 1-103. URL: http: // support.dce. felk . cvut.cz/mediawiki/images/5/56/Diz_2013_privara_samuel. pdf. 
[83] J. Qin and S. Wang. "A fault detection and diagnosis strategy of VAV air-conditioning systems for improved energy and control performances." In: Energy and Buildings 37.10 (2005), pp. 1035 -1048.

[84] S. Wang and Z. Ma. "Supervisory and Optimal Control of Building HVAC Systems: A Review". In: HVAC and R Research 14.1 (Jan. 2008), pp. 3-32. ISSN: 1078-9669. DOI: 10.1080/10789669.2008 . 10390991. URL: http://www.inf ormaworld.com/openurl?genre= article.

[85] M Sourbron and L Helsen. "Dynamic thermal behaviour of buildings with concrete core activation". KULeuven, 2012. ISBN: 9789460185724. URL: https://lirias.kuleuven .be/handle/123456789/396689.

[86] J. Široký et al. "Experimental analysis of model predictive control for an energy efficient building heating system". In: Applied Energy 88.9 (Sept. 2011), pp. 3079-3087. ISSN: 03062619. DOI: 10.1016/ j. apenergy .2011.03.009. URL: http: // linkinghub.elsevier . com/retrieve/pii/S0306261911001668.

[87] G. Pattarello. "MPC of HVAC systems: Design and implementation on a Real Case study". U. di Padova, 2013, pp. 1-105. URL: http: //tesi.cab.unipd.it/43642/1/main.pdf.

[88] S. C Bengea et al. "Model Predictive Control for Mid-Size Commercial Building HVAC : Implementation, Results and Energy Savings". In: Unknown (2012), pp. 979-986.

[89] J Siroki. "Active fault detection and control". University of West Bohemia, Pilsen (ZÃąpadoÄßesk Ãą univerzita v Plzni), 2012, pp. 196. URL: http://hdl.handle.net/11025/10781.

[90] D. Sturzenegger et al. "Model Predictive Control of a Swiss Office Building”. In: Proceedings of Clima 2013 conference 99.0 (2014). Pubication 4327 (mail), pp. 0-0. URL: http: / / www . opticontrol. ethz.ch/Lit/Stur_13_Proc-Clima2013.pdf.

[91] M. Gruber, A. Truschel, and J.-O. Dalenback. "Motion sensors for ventilation system control in office buildings". In: Journal of Energy (Hindawi) (2013).

[92] M. Castilla et al. "A comparison of thermal comfort predictive control strategies". In: Energy and Buildings 2010 (June 2011). ISSN: 03787788. DOI: $10.1016 / \mathrm{j}$.enbuild.2011.06.030. URL: http:// linkinghub.elsevier.com/retrieve/pii/S0378778811002799. 
${ }_{1231}[93] \quad$ S. R. West, J. K. Ward, and J. Wall. "Trial results from a model predictive control and optimisation system for commercial building \{HVAC\}". In: Energy and Buildings 72.0 (2014), pp. 271 -279. ISSN: 0378-7788. DOI: http://dx.doi.org/10.1016/j.enbuild. 2013 . 12.037. URL: http://www.sciencedirect.com/science/article/ pii/S0378778813008542.

[94] M. Y. Lamoudi, P. P. Beguery, and M. Alamir. "Use of simulation for the validation of a model predictive control strategy for energy management in buildings". In: 2011. URL: http://www.ibpsa.org/ proceedings/BS2011/P_1842.pdf (visited on 12/10/2014).

[95] Y. Yu et al. "Application of system identification and numerical optimization to a floor radiant heating control in a Solar House". In: $R E$ HVA world congress, Clima 2007 (2007), pp. 1-9. URL: http://www . $\mathrm{cmu}$. edu/iwess/publications/yuebin\_paper/applicationsysiclopt . pdf.

[96] Braun J.E., Montgomery K.W., and Chaturvedi N. "Evaluating the Performance of Building Thermal Mass Control Strategies". In: HVACER Research 88.4 (June 2001), pp. 403-428. DOI: 10.1080/10789669. 2001.10391283. URL: http://dx .doi .org/10 .1080/10789669 . 2001.10391283 .

[97] Airmaster et al. Project Haystack: an open source initiative to streamline working with data from the Internet of Things. 2014. URL: Availableonline, athttp://project-haystack.org/

[98] H. Strasser. IEA ECB Annex 63: Implementation of Energy strategies in Communities. accessed on 15/05/2015. 2014. URL: http://www . iea-ebc.org/fileadmin/user_upload/docs/Facts/EBC_Annex_ 63_Factsheet.pdf.

[99] Georgios Mavromatidis. "Model-based design of distributed urban energy systems underuncertainty (preprint)". Thesis. ETH Zurich, 2016.

[100] Liesje Van Gelder. Faculty of Engineering Science A probabilistic design methodology for building performance optimisation. December. 2014, p. 162. ISBN: 9789460189326. 
1264 [101] Daniel Coakley, Paul Raftery, and Marcus Keane. "A review of meth-

1265

1266

1267

1268

1269

1270

1271

1272

1273

1274 ods to match building energy simulation models to measured data". In: Renewable and Sustainable Energy Reviews 37 (2014), pp. 123141. ISSN: 13640321 . DOI: $10.1016 / \mathrm{j} . \mathrm{rser} .2014 .05 .007$, URL: http://dx.doi.org/10.1016/j.rser.2014.05.007.

[102] Mohammad Rasouli et al. "Uncertainties in energy and economic performance of HVAC systems and energy recovery ventilators due to uncertainties in building and HVAC parameters". In: Applied Thermal Engineering 50.1 (2013), pp. 732-742. ISSN: 13594311. DOI: 10 . 1016 / j . applthermaleng . 2012 . 08 . 021. URL: http : / / ww . sciencedirect.com/science/article/pii/S1359431112005431. 